\title{
A comparison of the chemical sinks of atmospheric organics in the gas and aqueous phase
}

\author{
S. A. Epstein and S. A. Nizkorodov \\ Department of Chemistry, University of California, Irvine, Irvine, CA, USA \\ Correspondence to: S. A. Epstein (scott.a.epstein@gmail.com) \\ Received: 24 March 2012 - Published in Atmos. Chem. Phys. Discuss.: 19 April 2012 \\ Revised: 19 July 2012 - Accepted: 27 August 2012 - Published: 12 September 2012
}

\begin{abstract}
Photochemical reactions represent the main pathway for the removal of non-methane volatile organic compounds (VOCs) in the atmosphere. VOCs may react with hydroxyl radical $(\mathrm{OH})$, the most important atmospheric oxidant, or they can be photolyzed by actinic radiation. In the presence of clouds and fog, VOCs may partition into the aqueous phase where they can undergo aqueous photolysis and/or reaction with dissolved $\mathrm{OH}$. The significance of direct aqueous photolysis is largely uncertain due to the lack of published absorption cross sections and photolysis quantum yields. In light of this, we strive to identify atmospherically relevant VOCs where removal by aqueous photolysis may be a significant sink. The relative importance of different photochemical sinks is assessed by calculating the ratios of the removal rates inside air parcels containing cloud and fog droplets. This relative approach provides useful information in spite of the limited aqueous photolysis data. Results of this work should help guide researchers in identifying molecules that are the most likely to undergo aqueous $\mathrm{OH}$ oxidation and photolysis. For example, we find that out of the 27 atmospherically relevant species investigated, the removal of glyceraldehyde and pyruvic acid by aqueous photolysis is potentially an important sink. We also determine the relative magnitudes of these four chemical sinks for the set of relevant organic compounds.
\end{abstract}

\section{Introduction}

Organic compounds play a key role in the chemistry of the atmosphere. Global emissions of non-methane volatile organic compounds (VOCs) total approximately $1300 \mathrm{Tg} \mathrm{C} \mathrm{yr}^{-1}$ (Atkinson and Arey, 2003; Goldstein and Galbally, 2007).
It is estimated that $130-270 \mathrm{Tg} \mathrm{Cyr}^{-1}$ of emitted VOCs are removed by dry and wet deposition, while the remaining $1030-1170 \mathrm{Tg} \mathrm{C} \mathrm{yr}^{-1}$ are transformed by chemical reactions. Oxidation by hydroxyl radical is the most important atmospheric sink for many VOCs (Andreae and Crutzen, 1997). Gas phase photolysis can also be important for certain classes of compounds including carbonyls (Moortgat, 2001), peroxides (Lee et al., 2000), and organic nitrates (Atkinson, 1990). In the presence of clouds and fog, VOCs may partition into the aqueous phase to various extents depending on their solubility. As in the gas phase, $\mathrm{OH}$ is the main oxidant for the transformation of aqueous organics in cloud and fog droplets (Ervens et al., 2011). Direct photolysis in the aqueous phase can also be an important sink depending on the chemical functionality of the species (Vione et al., 2006; Graedel and Goldberg, 1983).

Given the complexity of possible VOC photo-oxidation mechanisms and products, we strive to classify compounds by the rate at which they are removed by gaseous $\mathrm{OH}$ oxidation, gaseous photolysis, aqueous $\mathrm{OH}$ oxidation, and direct aqueous photolysis. We develop a framework to compare these four rates of removal for a subset of compounds identified as likely contributors to the water-soluble fraction of atmospheric particles (Saxena and Hildemann, 1996). Figure 1 is a schematic of our analysis showing the four chemical sinks under investigation and the dimensionless parameters we derive to represent the behavior of the selected VOCs. Direct liquid photolysis is parameterized into a photolysis rate constant that depends on the actinic flux of solar radiation, the quantum yield of photolysis, and the absorption cross section of the absorbing species. In contrast to the wealth of photochemical studies of organic molecules in the gas-phase, in organic solvents, glassy solids, and rare-gas matrices, 


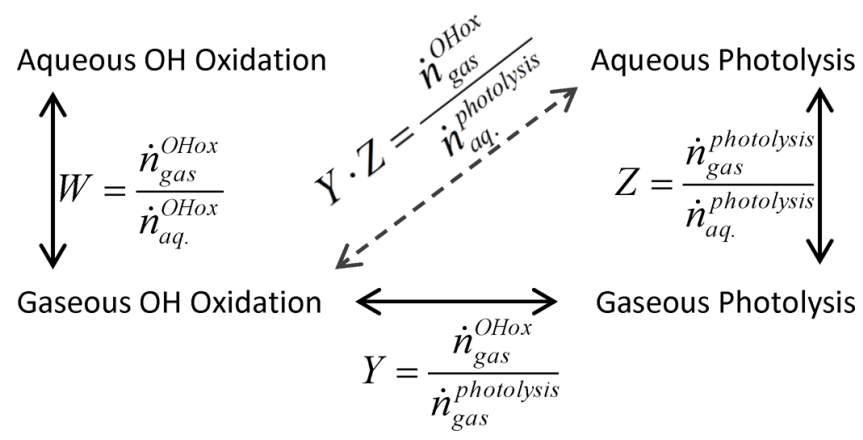

Fig. 1. Schematic diagram detailing the four chemical sinks being investigated in this manuscript. Dotted $\dot{n}$ represents the rate of change in moles per time per volume of air parcel due to each of the 4 processes: gaseous oxidation by $\mathrm{OH}\left(\dot{n}_{\text {gas }}^{\text {OHox }}\right)$, aqueous oxidation by $\mathrm{OH}\left(\dot{n}_{\mathrm{aq} .}^{\mathrm{OHox}}\right)$, gaseous photolysis $\left(\dot{n}_{\text {gas }}^{\text {photolysis }}\right)$, and aqueous photolysis $\left(\dot{n}_{\text {aq. }}^{\text {photolysis }}\right)$. The ratios of the removal rates $W, Z$, and $Y$ are defined in the text; they are independent of the air parcel volume. From these three ratios, the relative rates of any of these four processes can be calculated; an example is shown with a broken arrow.

measurements of photolysis quantum yields of organic compounds in water are more limited. The photochemistry treatise by Calvert and Pitts (1966) describes a few early aqueous photolysis studies of organic compounds, most of which were done under $254 \mathrm{~nm}$ irradiation. Only a handful of additional photolysis quantum yield studies in aqueous solutions under irradiation conditions that are relevant for the lower atmosphere $(\lambda>280 \mathrm{~nm})$ have appeared since then. Examples include photolysis of a number of organic pesticides (Vione et al., 2006; Wan et al., 1994), aromatic carbonyls (Ledger and Porter, 1972), substituted phenols (Czaplicka, 2006; Albinet et al., 2010), substituted benzyl derivatives (Zimmerman and Sandel, 1963), small aldehydes without correction for hydration (Hirshberg and Farkas, 1937), dicarbonyls such as biacetyl (Faust et al., 1997), hydrogen peroxide (Chu and Anastasio, 2005; Goldstein et al., 2007), methyl peroxide (Epstein et al., 2012), and pyruvic acid (Leermakers and Vesley, 1963; Larsen and Vaida, 2012; Guzmán et al., 2006, 2007). This data set is too meager for the development of a conceptual treatment of quantum yields or even an educated estimation for the selected atmospherically relevant compounds. In the absence of aqueous absorption cross section and quantum yield data for most organics, we aim to identify systems where direct aqueous photolysis is potentially a significant sink. While photolysis of certain organic compounds may generate $\mathrm{OH}$ radical in the gaseous or aqueous phase (Zellner et al., 1990; Epstein et al., 2012; Faust and Allen, 1993; Faust, 1994; Chu and Anastasio, 2005; Monod et al., 2007), we investigate direct photolysis and $\mathrm{OH}$ oxidation independently. Direct photolysis and indirect photolysis (reaction with oxidants formed by photolytic reactions) are linked by the potential generation of $\mathrm{OH}$ in the photolysis of certain organic compounds. However, $\mathrm{OH}$ yields from direct photolysis of most organic compounds are uncertain and depend on the photolytic mechanism. With published $\mathrm{OH}$ rate constants for oxidation in the gas and aerosol phase, along with absorption cross section and quantum yield data for photolysis in the gas phase, we can estimate the significance of these four chemical sinks to better understand the chemical fate of water soluble atmospheric organics. We stress that this is not a modeling study - our goal is to help guide researchers in identifying molecules that are the most likely to undergo aqueous $\mathrm{OH}$ oxidation and/or direct photolysis.

We ignore several other VOC chemical sinks to simplify our analysis and focus on the competition between oxidation by $\mathrm{OH}$ and photolysis. For example, alkenes are susceptible to oxidation by ozone (Bailey, 1978) and $\mathrm{NO}_{3}$ (Atkinson, 1991) but we are not investigating any olefinic compounds. On a global scale, organics may react with $\mathrm{Cl}$ atoms, however this is thought to be a minor VOC loss process (Atkinson and Arey, 2003). For specific compounds under certain conditions, aqueous reactions with dissolved sulfur dioxide in cloud and fog droplets may be significant (Finlayson-Pitts and Pitts, 2000). In addition, organic compounds can take part in various isomerization, oligomerization, and hydrolysis reactions, which are often catalyzed by inorganic constituents of the droplets such as acids. Biological activity may also lead to the destruction of dissolved organics in cloud droplets. Microbes can drive the oxidation of carbonaceous compounds during periods with low dissolved $\mathrm{OH}$ concentrations in cloud droplets (Vaitilingom et al., 2010). We also neglect potential photosensitization processes from contaminants dissolved in atmospheric waters (Vione et al., 2006).

\section{Methods}

Out of the oxygenated organic compounds identified by Saxena and Hildemann (1996) we choose a subset of 27 compounds for which there is the required experimental data published in the literature. These selected compounds contain a range of functionalities: monocarboxylic acids, dicarboxylic acids, aldehydes, ketones, keto-carboxylic acids, ethers, and peroxides. While a similar analysis for a series of nitrogencontaining organic compounds is beyond the scope of this manuscript, we also investigate methyl nitrate, the simplest organic nitrate. With the exception of tartaric acid and malic acid, all compounds are either intermediate-volatility organic compounds (IVOCs) or volatile organic compounds (VOCs); the majority of their mass partitions in the vapor phase as opposed to the condensed phase. Tartaric acid and malic acid are low-volatility organic compounds (LVOCs, $C^{*} \approx 1.6 \times 10^{-2} \mu \mathrm{g} \mathrm{m}^{-3}$ and $C^{*} \approx 2.4 \mu \mathrm{g} \mathrm{m}^{-3}$, respectively, Pankow and Asher, 2008) indicating that the majority of their mass will partition to the condensed phase in almost all atmospheric conditions (Donahue et al., 2009). The oxygen to 
carbon ratio of the selected compounds ranges from 0 to 2 . A full list of the compounds used and their corresponding references is presented in the Supplement. All of the IVOCs and VOCs are delivered to cloud and fog droplets by gaseous diffusion. However, tartaric acid and malic acid, as components of particulate matter, may also be delivered to the aqueous phase by particle scavenging, known to be very efficient in clouds (Limbeck and Puxbaum, 2000). For each of the compounds studied, we assume that the partitioning between the gaseous and aqueous phase is in a local state of equilibrium. Because of the variability of transport processes and competing reactions, equilibrium may not be completely established in all cases (Winiwarter et al., 1994; Audiffren et al., 1998). For example, complete equilibrium is unlikely when water droplets of different sizes and $\mathrm{pHs}$ are present or in the case of an air mass with a variable liquid water content. Henry's law may not hold in the presence of irreversible chemical reactions that are fast enough to prevent the establishment of equilibrium (Finlayson-Pitts and Pitts, 2000), in droplets that are not well mixed (Finlayson-Pitts and Pitts, 2000), clouds that have been recently formed (Chaumerliac et al., 2000), or droplets that are not sufficiently dilute (Seinfeld and Pandis, 1998). In polluted environments, organics may enter cloud or fog droplets through the dissolution of organic aerosol particles potentially resulting in aqueous concentrations that exceed equilibrium values. However, for atmospheric gases at typical concentrations, Henry's law reasonably approximates equilibrium with cloud or fog droplets (Seinfeld and Pandis, 1998), and our equilibrium-based calculations should therefore provide a good first-order estimate for the magnitude of aqueous phase processes. In the presence of high ion concentrations, Henry's law constants can be modified with Setchenow coefficients (De Bruyn et al., 1995; Kolb et al., 1997). However, in order to streamline the analysis and maintain its generality, we assume that each of the compounds studied do not interact with each other or other inorganic compounds typically found in cloud or fog droplets.

\subsection{Comparison of aqueous and gaseous photolysis}

For atmospheric organics, the implications of direct aqueous photolysis (Bateman et al., 2011; Schwarzenbach et al., 2005; Nguyen et al., 2012) are elusive due to the lack of literature data. However, the direct gaseous photolysis of atmospheric organics is well-studied (Atkinson et al., 2006; Sander et al., 2011). We strive to exploit the likely similarities in these processes in order to constrain the magnitude of aqueous phase photolysis by comparison with gas phase photolysis. The photolysis rate constant, $J$, is calculated with the following integral:

$J=\int F_{\mathrm{A}}(\lambda) \cdot \phi(\lambda) \cdot \sigma(\lambda) \cdot \mathrm{d} \lambda$

where $F_{\mathrm{A}}$ is the actinic flux, $\Phi$ is the quantum yield of photolysis, and $\sigma$ is the absorption cross section, all functions of wavelength, $\lambda$. In the absence of aqueous quantum yields and/or absorption cross sections, we can constrain the ratio of the gas phase and aqueous phase rate constants for a particular compound using educated assumptions on how its photochemistry is affected by dissolution in water. The actinic flux can be enhanced slightly inside a cloud droplet compared to the interstitial space (Finlayson-Pitts and Pitts, 2000). The maximum enhancement in the average actinic flux, calculated in Mayer and Madronich (2004), from work originally detailed in Madronich (1987) and Ruggaber et al. (1997) is 1.26 and 1.33 , respectively. The solvent has the potential to change the absorption cross sections upon dissolution, known as solvatochromism (Marini et al., 2010), however, this effect is likely insignificant for the set of compounds that we are investigating. Xu et al. (1993) finds that the absorption cross section shifts by about $10 \mathrm{~nm}$ to the blue and the intensity increases by $15-35 \%$ for a series of small ketones when they are dissolved in water. For hydrogen peroxide (Graedel and Weschler, 1981) and methyl peroxide (Epstein et al., 2012), the absorption cross sections of the gas and aqueous phases are similar. The magnitude of the change in quantum yield is far less certain. For direct aqueous photolysis, the quantum yield is generally lower than the corresponding gasphase value because energy dissipation due to collisions with the solvent molecules (cage effect) depresses the quantum yield in solution (Calvert and Pitts, 1966; Farkas and Hirshberg, 1937). However, in certain cases the yield may actually increase if the electronically excited molecule can undergo a reaction with solvent molecules. Few experimental measurements of aqueous quantum yields exist, making attempts to constrain the change in quantum yield upon dissolution difficult. To obtain an upper estimate of aqueous phase photolysis, we will assume that the quantum yield in solution is less than or equal to the gas-phase quantum yield.

To constrain the ratio of the rate of removal due to gaseous and aqueous photolysis we consider a system with an air parcel containing liquid water droplets and a pollutant $x$, which is in equilibrium between the gaseous and aqueous phase. The parcel has a liquid water content (LWC) defined in units of mass of liquid water per volume of air. The ratio of the rate of gaseous photolysis and aqueous photolysis for species $x$ is defined by the parameter $Z$ :

$Z=\frac{\frac{\mathrm{d} x_{x+h v}^{\text {gas }}}{\mathrm{d} t}}{\frac{\mathrm{d} n_{x+h v}^{\mathrm{q}}}{\mathrm{d} t}}=\left(R \cdot T \cdot \mathrm{LWC}_{\mathrm{v}} \cdot k_{H x}\right)^{-1}\left(\frac{J_{x+h v}^{\mathrm{gas}}}{J_{x+h v}^{\mathrm{aq}}}\right)$

where $n_{x+h v}$ is the moles of species $x$ undergoing photolysis in the gas or aqueous phase in a given volume of air, $t$ represents time, $R$ is the gas constant, $T$ is temperature, $\mathrm{LWC}_{\mathrm{v}}$ is the volume based liquid water content in units of volume of liquid water per volume of air, $k_{H x}$ is the effective Henry's law constant for species $x$ in units of molar concentration per pressure, $J^{\text {gas }}$ and $J^{\text {aq }}$ are the photolysis rate constants of species $x$ in the gaseous and aqueous phase, respectively. The ratio of the rates does not depend on the concentration 
of species $x$ because we assume that the gaseous and aqueous forms are in equilibrium. Derivations of all significant equations are presented in Appendix A.

Equation (2) is a model for systems where the species of interest does not hydrate or dissociate in the aqueous phase. However, photolabile carbonyls hydrate in the aqueous phase to form the corresponding gem-diol (Bell and McDougall, 1960). Using a generic mono-aldehyde as an example, we can write:

$$
\mathrm{RCHO}+\mathrm{H}_{2} \mathrm{O} \stackrel{K_{\text {hyd }}}{\longleftrightarrow} \mathrm{RC}(\mathrm{OH})_{2}
$$

where $K_{\text {hyd }}$ is the hydration equilibrium constant. We define the variable $\alpha_{N}$ as the fraction of the species that is present in form $N$ upon dissolution. For a monocarbonyl, there may be two forms in solution: the free molecule and the hydrated molecule. For a small dicarbonyl, there may be three forms in solution: the free molecule, the partially hydrated molecule, and the fully hydrated molecule. For a mono-carbonyl:

$\alpha_{\text {free }}=\left(K_{\text {hyd }}+1\right)^{-1}$ and $\alpha_{\text {hyd }}=\left(K_{\text {hyd }}^{-1}+1\right)^{-1}$

where $\alpha_{\text {free }}$ is the fraction of the free molecule in solution and $\alpha_{\text {hyd }}$ is the fraction of the hydrated molecule in solution. Aldehydes hydrate to a larger extent than ketones. For most ketones, only a small fraction of molecules exist in the gemdiol form (Bell and Gold, 1966). This has significant implications for photolysis as gem-diols do not absorb actinic UV radiation, and therefore are not photolabile in the atmosphere. We make a simplifying assumption that if we normalize the photolysis rate constant of the free form of species $x$ to unity, the photolysis rate constant of the fully hydrated form will be null, and in the special case of a dicarbonyl, the normalized photolysis rate constant of the partially hydrated form will be half of the free form because one of the photoactive carbonyls has been converted to non-photoactive gem-diol form. We define this normalized photolysis rate constant as $\beta_{N}$ :

$\beta_{\text {free }}=1, \beta_{\text {hyd }}=0$,

in the case of a dicarbonyl $\beta_{\text {part-hyd }}=1 / 2$

Therefore, in the case of a hydrating carbonyl, $x$, we can penalize the aqueous rate constant by the following factor, $\gamma_{x}$ :

$\gamma_{x}=\sum_{N} \alpha_{N} \cdot \beta_{N}$

where $\gamma_{x} \leq 1$. Using this factor in Eq. (2) allows us to continue using the effective Henry's law constant of species $x$ despite the fact that $x$ may hydrate into multiple forms in solution:

$Z=\frac{\frac{\mathrm{d} n_{x+h v}^{\mathrm{gas}}}{\mathrm{d} t}}{\frac{\mathrm{d} n_{x+h v}^{\mathrm{aq}}}{\mathrm{d} t}}=\left(R \cdot T \cdot \mathrm{LWC}_{\mathrm{v}} \cdot k_{H x}\right)^{-1}\left(\frac{J_{x+h v}^{\mathrm{gas}}}{\gamma_{x} \cdot J_{x+h v}^{\mathrm{aq}}}\right)$
Because $\gamma_{x}$ is always less than unity, the maximum effective photolysis rate is reduced in the aqueous phase for all carbonyls.

Finally, Henry's Law constants are strongly dependent on temperature. We perform calculations of $Z$ at $298 \mathrm{~K}$ where most constants are measured to ensure a straightforward analysis. However, in Appendix B, we describe a way of correcting these equations for the temperature effects.

\subsection{Comparison of aqueous and gaseous $\mathrm{OH}$ oxidation}

The majority of atmospheric organics are vulnerable to $\mathrm{OH}$ oxidation in both the gaseous and aqueous phase. We aim to elucidate the relative significance of each of these processes for our selected set of compounds by calculating the ratio of the rate of $\mathrm{OH}$ oxidation in the gas and aqueous phase. The most significant difference between this analysis and the previous discussion is that the rate constants due to $\mathrm{OH}$ oxidation in the aqueous (Ervens et al., 2003b; Buxton et al., 1988; Monod et al., 2005) and gaseous phases (Sander et al., 2011; Atkinson et al., 2006) have been experimentally determined for many atmospheric organics. Even if gas phase $\mathrm{OH}$ oxidation rate constants have not been measured, structure activity relationships are well developed, and provide accurate rate constant estimates (Atkinson, 1987, 1988; Kwok and Atkinson, 1995). We define $W$ as the ratio of the rate of gas phase $\mathrm{OH}$ oxidation of $x$ and the rate of aqueous phase $\mathrm{OH}$ oxidation of $x$. For non-ionizable species:

$$
W=\frac{\frac{\mathrm{d} n_{x+\mathrm{OH}}^{\mathrm{ga}}}{\mathrm{d} t}}{\frac{\mathrm{d} n_{x+\mathrm{OH}} \mathrm{q}}{\mathrm{d} t}}=\left(\mathrm{LWC}_{\mathrm{v}} \cdot k_{H x} \cdot R \cdot T\right)^{-1} \cdot\left(\frac{k_{x+\mathrm{OH}}^{\mathrm{gas}}}{k_{x+\mathrm{OH}}^{\mathrm{aq}}}\right) \cdot\left(\frac{C_{\mathrm{OH}}^{\mathrm{gas}}}{C_{\mathrm{OH}}^{\mathrm{aq}}}\right)
$$

Where $n_{x+\mathrm{OH}}$ represents the moles of $x$ undergoing oxidation by $\mathrm{OH}$ in the gas or aqueous phase, $k_{x+\mathrm{OH}}$ is the rate constant for $\mathrm{OH}$ oxidation with $x$ in the aqueous or gas phase, $C_{\mathrm{OH}}^{\mathrm{gas}}$ is the gas phase concentration of $\mathrm{OH}$ (moles of $\mathrm{OH}$ per volume of gas), and $C_{\mathrm{OH}}^{\mathrm{aq}}$ is the aqueous phase concentration of $\mathrm{OH}$ (moles of $\mathrm{OH}$ per volume of water). When using this equation, the units of $k_{x+\mathrm{OH}}$ and $C_{\mathrm{OH}}$ must be consistent so that the ratios of rate constants and concentrations are unitless.

Equation (8) can be used for species that hydrate because hydroxyl radical rate constants are typically tabulated for a solution containing all aqueous forms of the parent molecule (Ervens et al., 2003b; Monod et al., 2005). However, for species that ionize, we must use a modified version of Eq. (8) to account for the dissimilar aqueous $\mathrm{OH}$ rate constants of the ionized and native form. With measured $\mathrm{pK}_{a}$ values, we can calculate the fraction of the acid HA that is present in the ionized form $\left(f_{\mathrm{A}-}\right)$ and the native form $\left(f_{\mathrm{HA}}\right)$ at a given solution $\mathrm{pH}$.

$$
f_{\mathrm{A}^{-}}=\left(1+10^{\mathrm{pKA}-\mathrm{pH}}\right)^{-1} \quad f_{\mathrm{HA}}=\left(1+10^{\mathrm{pH}-\mathrm{pKA}}\right)^{-1}
$$


For a given $\mathrm{pH}$ and with $\mathrm{OH}$ rate constants for reaction with the acid, $k_{\mathrm{HA}+\mathrm{OH}}$, and its anion, $k_{\mathrm{A}}^{-}+\mathrm{OH}$, we can write $W$ as:

$$
\begin{gathered}
W=\frac{\frac{\frac{\mathrm{d} n_{\mathrm{HA}+\mathrm{OH}}^{\mathrm{gas}}}{\mathrm{d} t}}{\mathrm{~d} n_{\mathrm{HA}+\mathrm{A}^{-}+\mathrm{OH}}^{\mathrm{dq}}}}{\mathrm{d} t}\left(R \cdot T \cdot \mathrm{LWC}_{\mathrm{v}} \cdot k_{H x}\right)^{-1} \\
\left(\frac{k_{\mathrm{HA}+\mathrm{OH}}^{\mathrm{gas}}}{f_{\mathrm{HA}} \cdot k_{\mathrm{HA}+\mathrm{OH}}^{\mathrm{aq}}+f_{\mathrm{A}^{-}} \cdot k_{\mathrm{A}^{-}+\mathrm{OH}}^{\mathrm{aq}}}\right)\left(\frac{C_{\mathrm{OH}}^{\mathrm{gas}}}{C_{\mathrm{OH}}^{\mathrm{aq}}}\right)
\end{gathered}
$$

In this case, both the Henry's law constant and the rate constants are temperature dependent, but we perform calculations at $298 \mathrm{~K}$ where most experimental data is measured to keep our analysis as straightforward as possible. Appendix B describes a way for incorporating temerature effects in this equation.

\subsection{Comparison of gaseous $\mathrm{OH}$ oxidation and photolysis}

The comparison of gas phase $\mathrm{OH}$ oxidation and photolysis is also based on the ratio of the rates of each of these processes to cancel out the dependence on species concentration. We define $Y$ as the ratio of the rate of gas phase $\mathrm{OH}$ oxidation of species $x$ and the rate of gas phase photolysis of species $x$. At a constant temperature and pressure, $Y$ is a function of the solar zenith angle, SZA:

$Y(\mathrm{SZA})=\frac{\frac{\mathrm{d} x_{x+\mathrm{OH}}^{\text {gas }}}{\mathrm{d} t}}{\frac{\mathrm{d} n_{x+h \nu}^{\mathrm{gas}}}{\mathrm{d} t}}=\frac{k_{x+\mathrm{OH}}^{\mathrm{gas}} \cdot C_{\mathrm{OH}}(\mathrm{SZA})}{J_{x+h v}^{\mathrm{gas}}(\mathrm{SZA})}$

where $C_{\mathrm{OH}}(\mathrm{SZA})$ is the gas phase $\mathrm{OH}$ concentration as a function of the solar zenith angle in units that correspond to the units of $k_{x+\mathrm{OH}}$. This concentration is described by the empirical power-law function relating the $\mathrm{OH}$ concentration to the photolysis rate of $\mathrm{O}_{3} \rightarrow \mathrm{O}\left({ }^{1} \mathrm{D}\right)$ described in Rohrer and Berresheim (2006).

For species with measured absorption cross sections as a function of temperature and quantum yields as a function of temperature and/or pressure, we can go one step further and examine how $Y$ varies with atmospheric height and solar zenith angle.

$Y(\mathrm{SZA}, z)=\frac{\frac{\mathrm{d} n_{x+\mathrm{OH}}^{\text {gas }}}{\mathrm{d} t}}{\frac{\mathrm{d} n_{x+h \nu}^{\text {gas }}}{\mathrm{d} t}}=\frac{k_{x+\mathrm{OH}}^{\mathrm{gas}}(T) \cdot C_{\mathrm{OH}}(\mathrm{SZA}, T)}{J_{x+h \nu}^{\mathrm{gas}}(\mathrm{SZA}, z, T)}$

where the change in temperature at a given height in the atmosphere, $z$, is given by:

$$
-\frac{\mathrm{d} T}{\mathrm{~d} z}=\Gamma
$$

The parameter $\Gamma$ represents the lapse rate, for which we use the average value in the troposphere, $6.5 \mathrm{~K} \mathrm{~km}^{-1}$ (Wallace and Hobbs, 2006). The actinic flux as a function of solar zenith angle and wavelength is predicted with the Tropospheric Ultraviolet and Visible (TUV) Radiation Model (ACD, Edition 4.4).

\section{Results}

\subsection{Comparison of aqueous and gaseous photolysis}

Our comparison of aqueous and gaseous photolysis with Eqs. (2) and (7) provide an upper estimate to the extent of in-cloud photolysis for the following reasons. We perform this analysis using an air parcel at $298 \mathrm{~K}$ with a liquid water content of $0.5 \mathrm{~g} \mathrm{~m}^{-3}$, approximately the largest value that is routinely measured in the atmosphere based on measurements of stratus and cumulus clouds (Seinfeld and Pandis, 1998; Hobbs, 1993). Aqueous processes are more significant in wetter air parcels as a larger fraction of each organic resides in the aqueous phase. The results of our analysis are not highly sensitive to our reasonable maximum LWC selection. If we chose a value of $0.25 \mathrm{~g} \mathrm{~m}^{-3}$ instead, maximum rates of gaseous photolysis relative to rates of aqueous photolysis would only be doubled. This is unlikely to influence our conclusions, which are based on the order-of-magnitude estimates. In addition, aqueous quantum yields may be significantly depressed by solvent effects, thus slowing down the rate of aqueous photolysis relative to gaseous photolysis.

Figure 2 shows the results of this analysis for a series of atmospherically relevant, non-hydrating species, specifically peroxides and methyl nitrate. The ratio of gas and aqueous rate constants are shown on the axis of abscissas and the effective Henry's law constants are shown on the axis of ordinates. Colors and diagonal isopleths show the magnitude of $Z$. Molecules are labeled in order of increasing $Z$. References for the Henry's law parameters are presented in the Supplement. The $\mathrm{x}$-axis intentionally spans a large range to provide an indication of the sensitivity of this analysis. Actual values should lie somewhere to the right $\left(J_{\text {aqueous }}<J_{\text {gas }}\right)$ of our upper bound estimations.

Of the four molecules included in Fig. 2, only hydrogen peroxide has the potential for an appreciable aqueous photolysis removal rate relative to gas phase photolysis. With actual experimental data on the absorption cross sections and quantum yields of gaseous (Sander et al., 2011) and aqueous hydrogen peroxide (Chu and Anastasio, 2005), we can pinpoint the location of this molecule on the $\mathrm{x}$-axis more precisely. The two inward arrows adjacent to the hydrogen peroxide estimation point (1) on Fig. 2 detailing the experimentally measured range in $J_{\text {gas }} / J_{\text {aqueous }}$ from a solar zenith angle of $0-90^{\circ}$ shows that the actual value is moderately below our upper-bound estimate. Gelencsér and Varga (2005) estimate that multi-phase reactions become important relative to gasphase photo-oxidation processes when the effective Henry's law constant is greater than $10^{3} \mathrm{M} \mathrm{atm}^{-1}$. We find a similar threshold value in our analysis of the photolysis of nonhydrating species.

The series of atmospherically relevant, hydrating species is presented in Fig. 3. When experimental measurements of the Henry's Law constants were unavailable (malonic acid, succinic acid, malic acid, lactic acid, tartaric acid, and 


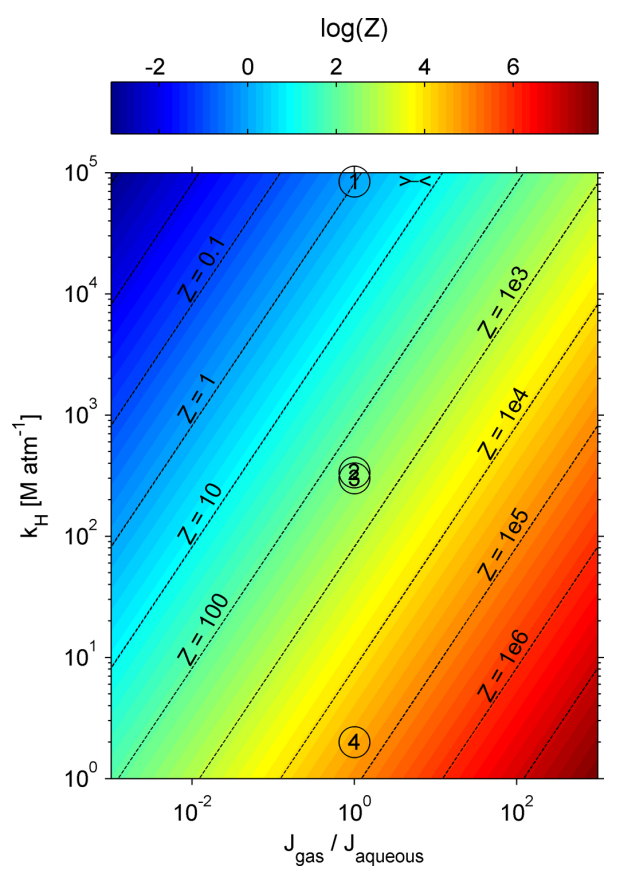

Fig. 2. Best estimate for the maximum ratio of gas phase photolysis to aqueous phase photolysis, $Z$, for a series of peroxides and methyl nitrate in an air parcel with a $L W C=0.5 \mathrm{~g} \mathrm{~m}^{-3}$ at $298 \mathrm{~K}$. Species are labeled in order of increasing $Z$ : (1) hydrogen peroxide, (2) ethyl peroxide, (3) methyl peroxide, and (4) methyl nitrate. The two inward arrows adjacent to " 1 " show the range of $Z$ for hydrogen peroxide across all solar zenith angles with experimentally measured gaseous and aqueous rate constants from (Sander et al., 2011; Chu and Anastasio, 2005).

glyceraldehyde), group contribution estimations were used (Saxena and Hildemann, 1996). Aqueous photolytic removal is potentially important in several of these species due to their large effective Henry's law parameters. Upper-bound estimates are not all centered about the $J_{\text {gas }} / J_{\text {aqueous }}=1$ line due to hydration into non-photolabile gem-diols in the aqueous phase. For example, at low concentrations, formaldehyde is almost exclusively in diol form (Dong and Dasgupta, 1986; Le Botlan et al., 1983). Therefore, formaldehyde (molecule \#13 in Fig. 3) is represented by the arrow pointing towards $J_{\text {gas }} / J_{\text {aqueous }}=\infty$. Aqueous photolytic removal of glyceraldheyde $\left(Z \leq 1.0 \times 10^{-4}\right)$ is potentially very significant. Aqueous removal of pyruvic acid $\left(Z \leq 2.7 \times 10^{-1}\right)$ is likely significant and aqueous removal of gluteraldehyde $(Z \leq 6.2)$, methyl glyoxal $(Z \leq 15)$, glyoxal $(Z \leq 20)$, glycolaldehyde $(Z \leq 22)$, and glyoxylic acid $(Z \leq 29)$ has the potential to be somewhat important. Ethers and compounds with only carboxylic acid functionality were not analyzed because they are not photolabile under typical tropospheric conditions (Chebbi and Carlier, 1996; Atkinson and Arey, 2003; Finlayson-Pitts and Pitts, 2000).

The y-axis of Figs. 2 and 3 provides a visual sensitivity analysis of our assumption of Henry's law equilibrium.

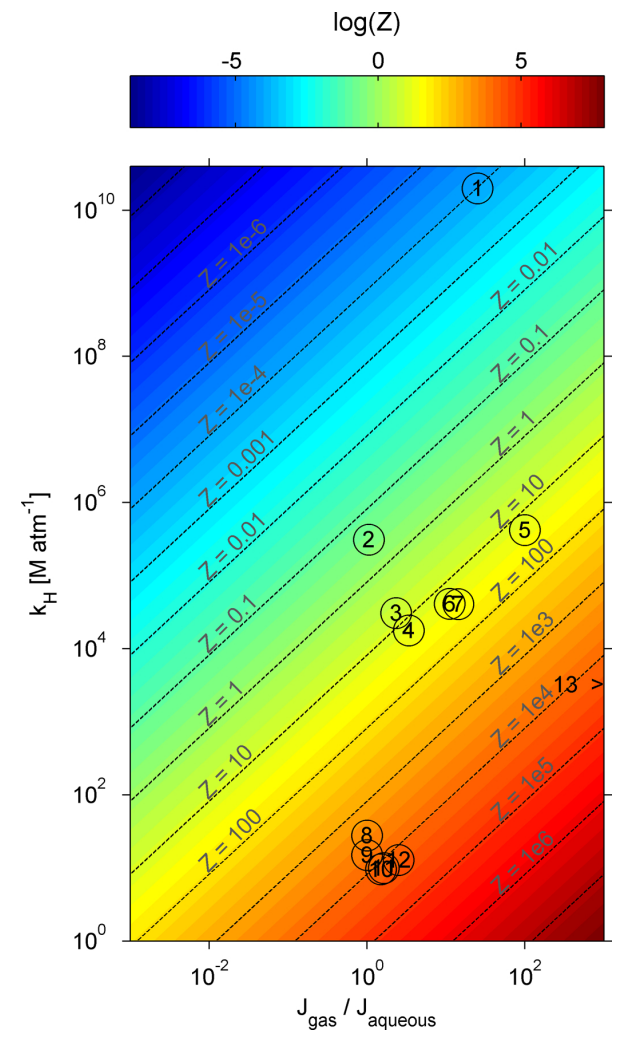

Fig. 3. Best estimate for the maximum ratio of gas phase photolysis to aqueous phase photolysis, $Z$, for a series of carbonyls in an air parcel with a $\mathrm{LWC}=0.5 \mathrm{~g} \mathrm{~m}^{-3}$ at $298 \mathrm{~K}$. The "> " label next to species 13 (formaldehyde) indicates that it lies at $Z \gg 10^{4}$ where $J_{\text {aqueous }} \sim 0$. Species are labeled in order of increasing $Z$ : (1) glyceraldehyde, (2) pyruvic acid, (3) gluteraldheyde, (4) methyl glyoxal, (5) glyoxal, (6) glycolaldehyde, (7) glyoxylic acid, (8) acetone, (9) butanone, (10) butanal, (11) propanal, (12) acetaldehyde, and (13) formaldehyde.

For specific atmospheric conditions, previous researchers quantify the departure from equilibrium as the ratio of the observed aqueous phase concentration of species " $x$ " and the predicted aqueous phase concentration with Henry's law from the observed gas phase concentration (Winiwarter et al., 1994; Leriche et al., 2000):

$\Re=\frac{C_{x}^{\mathrm{aq}}}{k_{H x} \cdot C_{x}^{\mathrm{gas}}}$

where the units of $k_{H x}$ correspond to the units of $C_{x}^{\text {gas }} / C_{x}^{\mathrm{aq}}$ as to make $\Re$ unitless. For specific atmospheric conditions where $\mathfrak{R}$ values are known, one can multiply the ordinate values by these factors to obtain a more realistic estimate of $Z$. Since $\Re$ is a function of local conditions, we only use the equilibrium values calculated from Henry's law to make our analysis as general as possible. 


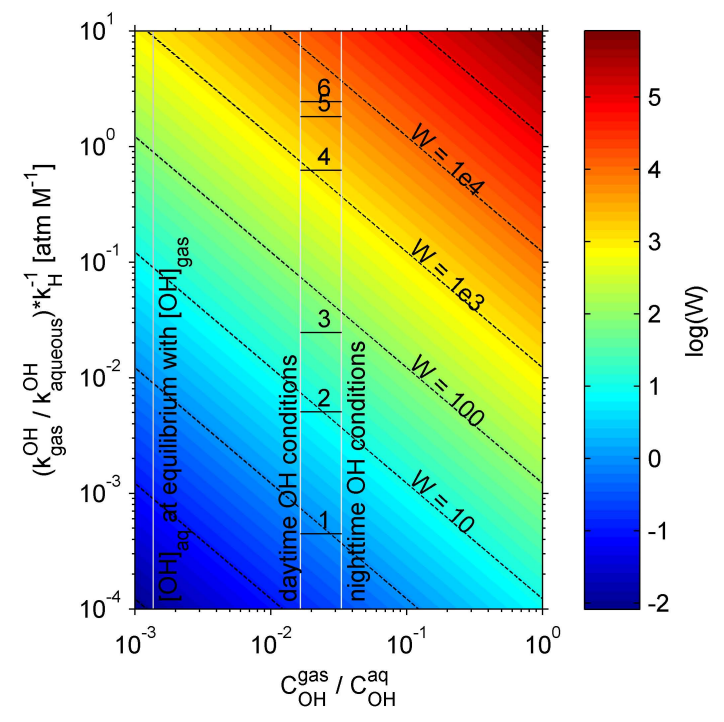

Fig. 4. The ratio of the rate of gas phase $\mathrm{OH}$ oxidation to the rate of aqueous phase oxidation for a series of peroxides and ethers in an air parcel with a liquid water content of $0.5 \mathrm{~g} \mathrm{~m}^{-3}$ at $298 \mathrm{~K}$. Labeled horizontal lines are bound by differences in $C_{\mathrm{OH}}^{\text {gas }} / C_{\mathrm{OH}}^{\text {aqueous }}$ (defined as the moles of $\mathrm{OH}$ per volume of air/the moles of $\mathrm{OH}$ per volume of liquid) during different times of the day. The line demarcating $\mathrm{OH}$ at Henry's law equilibrium is shown on the left side of the plot. Species are labeled in order of increasing $W:(1)$ hydrogen peroxide, (2) ethyl peroxide, (3) methyl peroxide, (4) methyl tert-butyl ether, (5) dimethyl ether, and (6) ethyl ether.

\subsection{Comparison of aqueous and gaseous $\mathrm{OH}$ oxidation}

The ratio of the hydroxyl radical concentration in the gas and aqueous phase is a key uncertainty in the evaluation of $W$ (the ratio of the rate of gas phase $\mathrm{OH}$ oxidation to aqueous phase $\mathrm{OH}$ oxidation). We use this $\mathrm{OH}$ ratio as one of our free parameters to allow for a sensitivity analysis, but present an educated guess to better constrain our results. For the gaseous $\mathrm{OH}$ concentration, we use the upper end of the measured and theoretical estimates suggested in Seinfeld and Pandis (1998), $C_{\mathrm{OH}}^{\text {daytime }}=1 \times 10^{7}$ molecules $\mathrm{cm}^{-3}$ and $C_{\mathrm{OH}}^{\text {nightime }}=2 \times 10^{5}$ molecules $\mathrm{cm}^{-3}$. For the aqueous $\mathrm{OH}$ concentration in a cloud or fog droplet, we use the recommended values in the review by Ervens et al. (2011) that were determined with theoretical models (Ervens and Volkamer, 2010; Ervens et al., 2003a): $C_{\mathrm{OH}}^{\text {daytime }}=10^{-13} \mathrm{M}$ and $C_{\mathrm{OH}}^{\text {nightime }}=10^{-14} \mathrm{M}$. The $\mathrm{OH}$ concentrations that we use are similar to the values assumed in Gelencsér and Varga (2005).

Figure 4 shows a graphical representation of Eq. (8) for a series of peroxides and ethers in an air parcel with a LWC of $0.5 \mathrm{~g} \mathrm{~m}^{-3}$ at $298 \mathrm{~K}$. The ratio of the gas and aqueous phase $\mathrm{OH}$ concentrations (moles of $\mathrm{OH}$ per volume of air/moles of $\mathrm{OH}$ per volume of liquid), which we will refer to as the "OH ratio", are shown on the x-axis. The product of the ratio of the gas and aqueous $\mathrm{OH}$ rate constants and the inverse

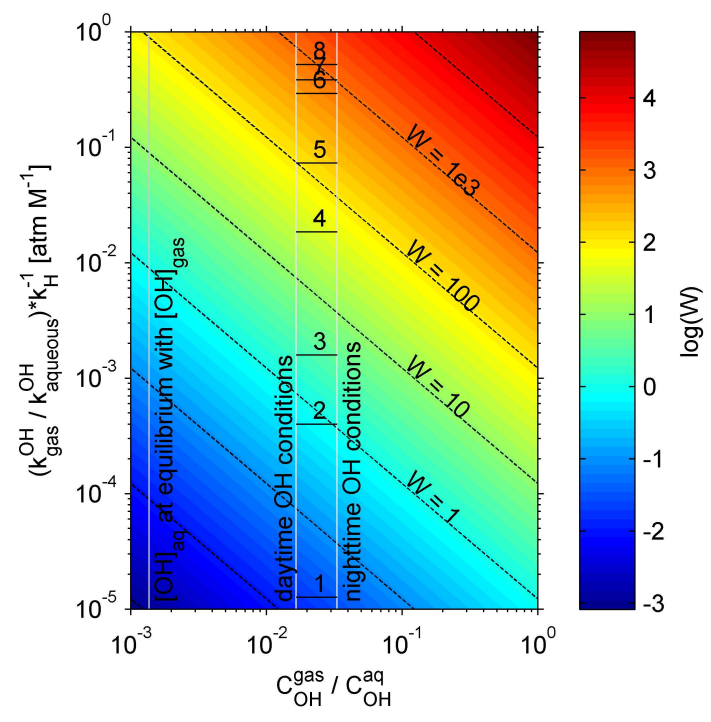

Fig. 5. The ratio of the rate of gas phase $\mathrm{OH}$ oxidation to the rate of aqueous phase oxidation for a series of carbonyls in an air parcel with a liquid water content of $0.5 \mathrm{~g} \mathrm{~m}^{-3}$ at $298 \mathrm{~K}$. Labeled horizontal lines are bound by differences in $C_{\mathrm{OH}}^{\mathrm{gas}} / C_{\mathrm{OH}}^{\text {aqueous }}$ (defined as the moles of $\mathrm{OH}$ per volume of air/the moles of $\mathrm{OH}$ per volume of liquid) during different times of the day. The line demarcating $\mathrm{OH}$ at Henry's law equilibrium is shown on the left side of the plot. Species are labeled in order of increasing $W:(1)$ glyoxal, (2) methyl glyoxal, (3) formaldehyde, (4) acetone, (5) 2-butanone, (6) acetaldehyde, (7) butanal, and (8) propanal.

Henry's law constant ( $\operatorname{atm~M}^{-1}$ ) is represented on the y-axis. Colors along with the diagonal isopleths indicate the magnitude of $W$. Each species is represented by a labeled horizontal line bound by our daytime and nighttime estimates in the $\mathrm{OH}$ ratio. Species are labeled in order of increasing $W$. A line showing the $\mathrm{OH}$ ratio in Henry's Law equilibrium (rarely realized in practice because of the high $\mathrm{OH}$ reactivity) is also presented for perspective. All of the rate constants are referenced in the Supplement. Based on this analysis, we find that $\mathrm{OH}$ oxidation of hydrogen peroxide is important in the aqueous phase. Gas-phase $\mathrm{OH}$ oxidation strongly dominates the removal of ethyl peroxide, methyl peroxide, methyl tert-butyl ether, dimethyl ether, and ethyl ether.

Figure 5 is a continuation of this evaluation for a series of carbonyls under the same conditions. Aqueous oxidation dominates the removal of glyoxal compared to gas phase oxidation under the conditions of high LWC. Also, aqueous reaction with $\mathrm{OH}$ is likely a significant sink in the removal of methyl glyoxal compared to gas phase oxidation. Removal of formaldehyde by aqueous oxidation may be more important depending on the $\mathrm{OH}$ ratio. Gaseous oxidation dominates the removal of acetone, 2-butanone, acetaldehyde, butanal, and propanal compared to aqueous oxidation by $\mathrm{OH}$.

Figure 6 shows a similar analysis for a series of carboxylic acids using Eq. (10) without color contours for simplicity. Molecules are represented by labeled rectangles instead of 


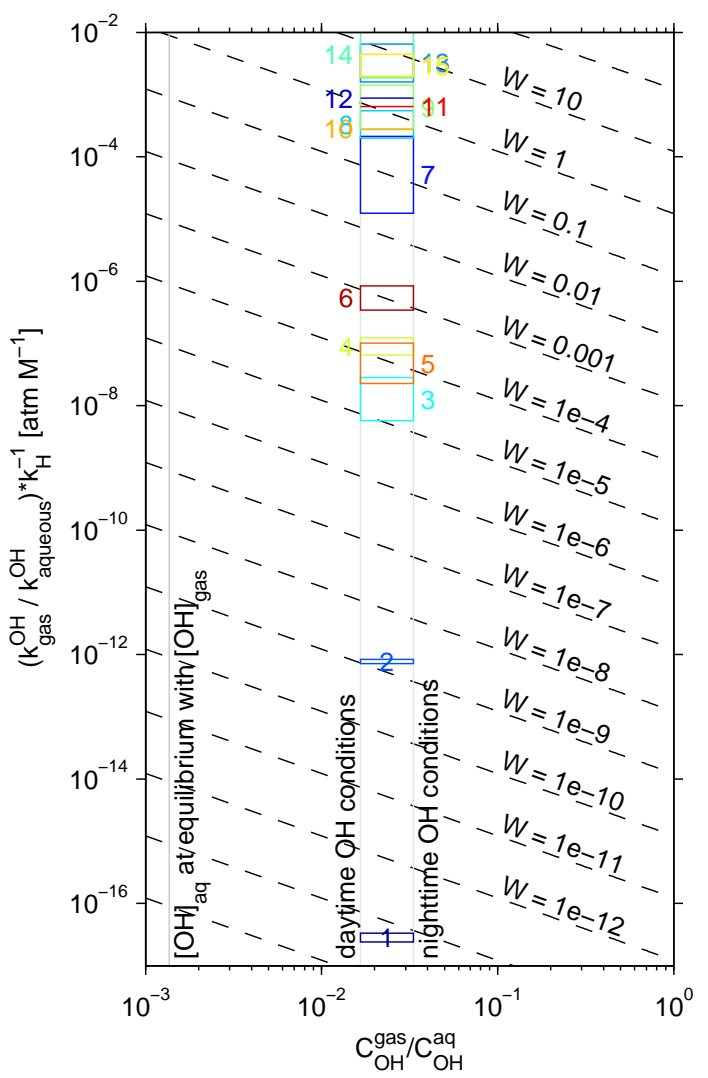

Fig. 6. The ratio of the rate of gas phase $\mathrm{OH}$ oxidation to the rate of aqueous phase oxidation for a series of acids in an air parcel with a liquid water content of $0.5 \mathrm{~g} \mathrm{~m}^{-3}$ at $298 \mathrm{~K}$. Labeled rectangles are bound by differences in $C_{\mathrm{OH}}^{\mathrm{gas}} / C_{\mathrm{OH}}^{\text {aqueous }}$ (defined as the moles of $\mathrm{OH}$ per volume of air/the moles of $\mathrm{OH}$ per volume of liquid) during different times of the day and the $\mathrm{pH}$ of the cloud or fog droplet ranging between 2 and 6 . The line demarcating $\mathrm{OH}$ at Henry's law equilibrium is shown on the left side of the plot. Species are labeled in order of increasing $W$ at $\mathrm{pH}=6$ : (1) tartaric acid (R,R), (2) malic acid, (3) malonic acid, (4) lactic acid, (5) succinic acid, (6) pyruvic acid, (7) formic acid, (8) propanoic acid, (9) glyoxylic acid, (10) 2-methyl propanoic acid, (11) pentanoic acid, (12) hexanoic acid, (13) acetic acid, (14) 3-methyl butanoic acid, and (15) 2,2dimethyl 1-propanoic acid.

horizontal lines due to the dependence of aqueous oxidation rates on $\mathrm{pH}$. Labeled rectangles are horizontally bound by estimates of the $\mathrm{OH}$ ratio in the daytime and nighttime. Rectangles are vertically bound by typical cloud or fog droplet pH from 2-6 (Finlayson-Pitts and Pitts, 2000). Species are labeled according to increasing $W$ at $\mathrm{pH} 6$. Aqueous removal by $\mathrm{OH}$ is an important sink compared to gaseous removal for all of the acids investigated here because of their large water solubilities. We expect aqueous $\mathrm{OH}$ oxidation to dominate in the removal of tartaric acid (R,R), malic acid, malonic acid, lactic acid, succinic acid, pyruvic acid, and formic acid. For specific cases where the $\Re$-values are known, the ordinate values can be corrected to represent the local conditions as shown in Sect. 3.1.

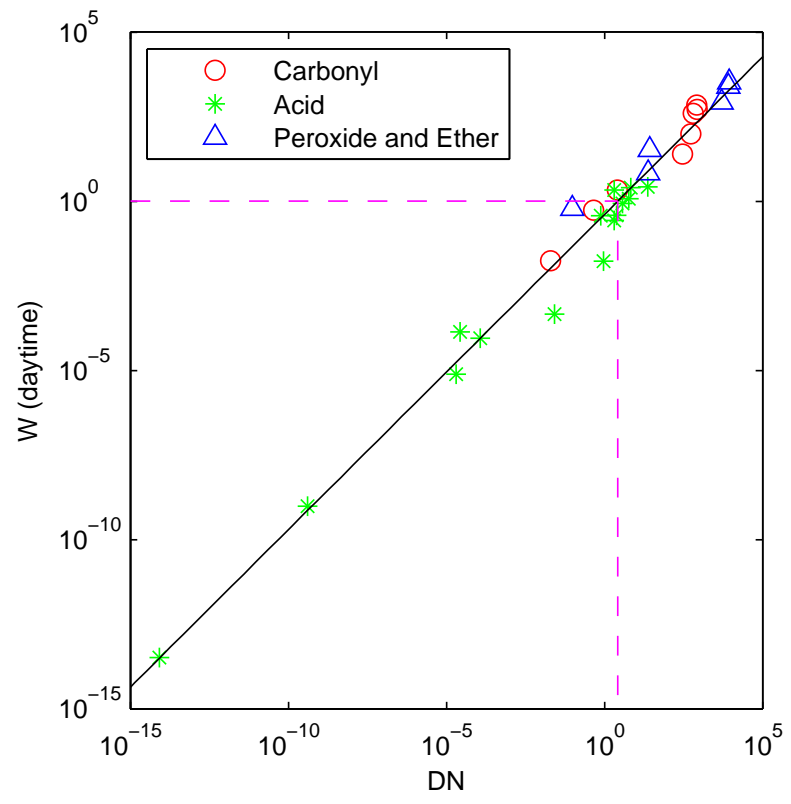

Fig. 7. The ratio of the rate of gas phase $\mathrm{OH}$ oxidation to the rate of aqueous phase oxidation, $W$ as a function of the dimensionless number, $\mathrm{DN}=\frac{1}{10}\left(\mathrm{LWC}_{\mathrm{V}} \cdot R \cdot T \cdot k_{H}\right)^{-1}$ for the series of compounds investigated under daytime $\mathrm{OH}$ concentrations in an air parcel with a $L W C=0.5 \mathrm{~g} \mathrm{~m}^{-3}$ at $298 \mathrm{~K}$. The magenta dashed line indicates the transition between gaseous reactions being more important, $\mathrm{DN} \gg 1$ and aqueous reactions being more important, DN $\ll 1$. Similar plots with nighttime $\mathrm{OH}$ concentrations and $\mathrm{LWC}=0.001 \mathrm{~g} \mathrm{~m}^{-3}$ are shown in the Supplement and yield an identical DN cutoff.

The vertical coordinate on Figs. 4-6 can be simplified because gas and aqueous $\mathrm{OH}$ rate constants are related for individual species. Most rate constants lie within a factor of 3 of a line relating $\log \left(k_{\text {gas }}^{\mathrm{OH}}\right)$ and $\log \left(k_{\text {aqueous }}^{\mathrm{OH}}\right)$ (Haag and Yao, 1992). In light of this relationship, the dimensionless number, DN, introduced in this work, is a reasonable predictor for the magnitude of $W$ for our range of assumed $\mathrm{OH}$ ratio where:

$\mathrm{DN}=\frac{1}{10}\left(\mathrm{LWC}_{\mathrm{v}} \cdot R \cdot T \cdot k_{\mathrm{H}}\right)^{-1}$

Figure 7 shows the predictive power of DN for the series of compounds investigated during daytime $\mathrm{OH}$ concentrations in an air parcel with a $L W C=0.5 \mathrm{~g} \mathrm{~m}^{-3}$ at $298 \mathrm{~K}$. When $\mathrm{DN} \gg 1$, gaseous $\mathrm{OH}$ oxidation is more important than aqueous phase oxidation. Aqueous phase oxidation is more important when $\mathrm{DN} \ll 1$. Both reactions are potentially significant when DN is on the order of unity. This relationship holds with air parcels containing different liquid water contents or parcels with nighttime $\mathrm{OH}$ concentrations; a multi-panel plot showing $W$ as a function of DN under different conditions is presented in the Supplement. 

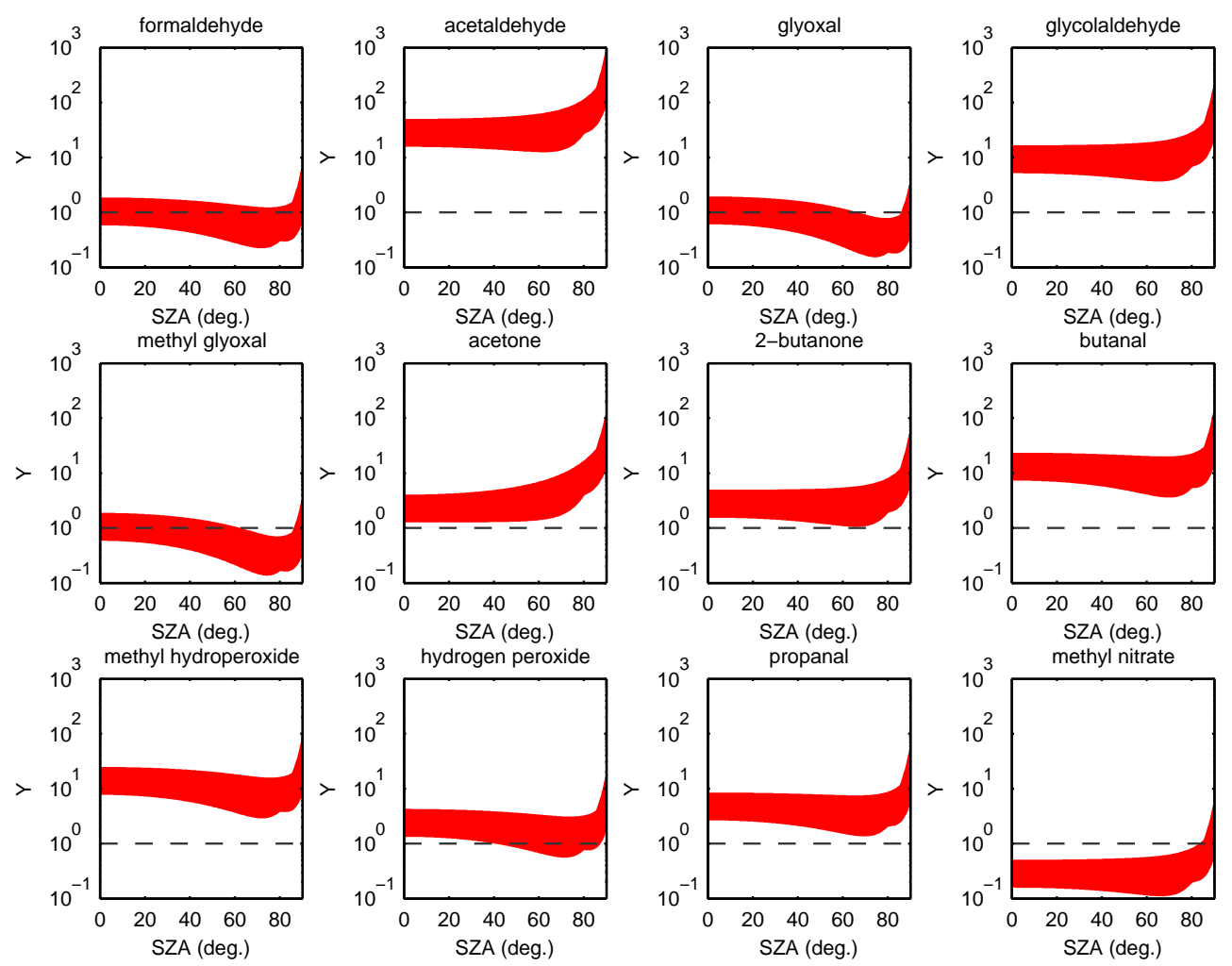

Fig. 8. The ratio of the rate of gas phase $\mathrm{OH}$ oxidation to the rate of gaseous photolysis, $Y$, as a function of solar zenith angle, SZA, for compounds where the absorption cross sections and quantum yields are published at $298 \mathrm{~K}$. The width of the red swath is due to the uncertainty in the empirical function relating $\mathrm{OH}$ concentration to the rate of $\mathrm{O}_{3}$ photolysis. The dashed line indicates where the rate of gas phase $\mathrm{OH}$ oxidation is equal to the rate of gaseous photolysis, $Y=1$.

\subsection{Comparison of gaseous $\mathrm{OH}$ oxidation and photolysis}

For a given species, the ratio of the rate of gas phase $\mathrm{OH}$ oxidation to the rate of gaseous photolysis, $Y$, is dependent on the solar zenith angle, temperature, and pressure (see Eq. 12). We first investigate a series of 12 compounds with published quantum yield and absorption cross section measurements at $298 \mathrm{~K}$ and $1 \mathrm{~atm}$ using Eq. (11). The references for these values are presented in the Supplement. Figure 8 shows how $Y$ varies with SZA for each of the selected compounds at sea level and $298 \mathrm{~K}$. The width of the red swathe is due to the uncertainty in the empirical function from Rohrer and Berresheim (2006) that correlates $\mathrm{OH}$ radical concentration with the photolysis rate of $\mathrm{O}_{3}$. The actinic flux at each wavelength as a function of SZA was predicted with the TUV Radiation Model (ACD, Edition 4.4) with a surface albedo of 0.154 , the globally averaged value from Hummel and Reck (1979), and an ozone column of 300 Dobson units. In general, the selected molecules exhibit suppressed rates of photolysis at SZA $>80$ degrees. For acetaldehyde, glycolaldehyde, acetone, 2-butanone, butanal, methyl peroxide, and propanal, gas phase oxidation is more important than photolysis at all SZA. Removal of methyl nitrate by photol- ysis is more significant than removal by $\mathrm{OH}$ oxidation. For formaldehyde, glyoxal, methyl glyoxal, and hydrogen peroxide, the relative importance of each of these removal processes is dependent on the SZA and the local $\mathrm{OH}$ concentration.

We also investigated this ratio as a function of SZA and altitude assuming a standard tropospheric lapse rate of $6.5 \mathrm{~K} \mathrm{~km}^{-1}$ (Wallace and Hobbs, 2006) and a scale height of $7.5 \mathrm{~km}$ for four compounds with published quantum yields and absorption cross section measurements as a function of temperature and pressure and $\mathrm{OH}$ rate constants as a function of temperature. See the Supplement for these references. In this case, the actinic flux was predicted as a function of wavelength, SZA, and altitude with a surface albedo of 0.154 and an ozone column of 300 Dobson units. Figure 9 shows a complicated dependence of $Y$ on altitude and SZA for each of the four species investigated. This analysis at the bounds of the $\mathrm{OH}$ concentration uncertainty is presented in the Supplement. 

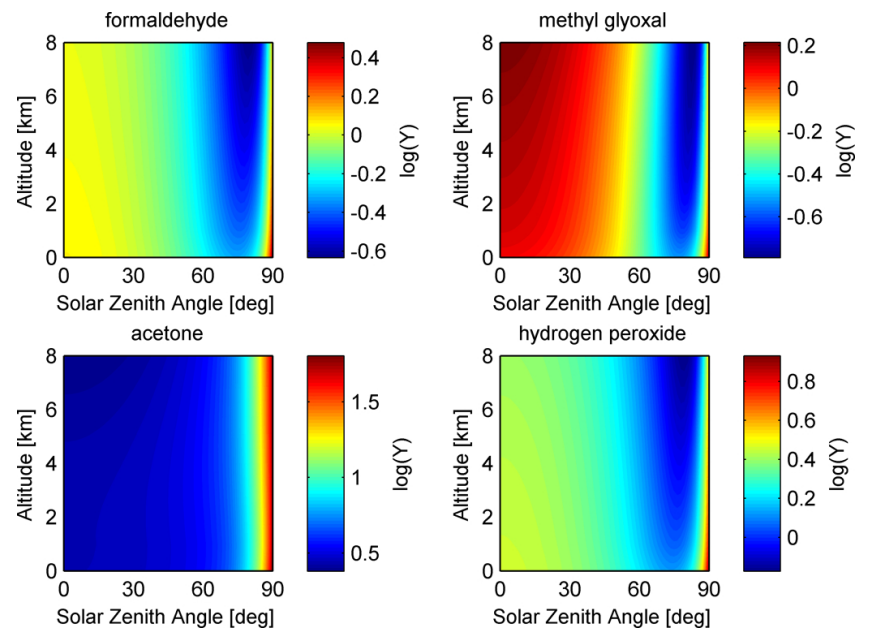

Fig. 9. The ratio of the rate of gas phase $\mathrm{OH}$ oxidation to the rate of gaseous photolysis, $Y$, as a function of solar zenith angle and altitude for compounds where the absorption cross sections and quantum yields are published as a function of temperature and pressure. Upper and lower limits of these plots, due to the uncertainty in the empirical function relating $\mathrm{OH}$ concentration to the rate of photolysis of $\mathrm{O}_{3}$ to $\mathrm{O}\left({ }^{1} \mathrm{D}\right)$, are presented in the Supplement.

\section{Atmospheric implications}

With knowledge of the three ratios, $W, Z$, and $Y$, which characterize the significance of each of the four chemical sinks investigated, we can calculate the relative contribution of each of the sinks for a specific compound. The results of this analysis are presented in Fig. 10 for compounds with a full set of requisite data in an air mass with a LWC $=0.05 \mathrm{~g} \mathrm{~m}^{-3}$ (characteristic of light clouds and fogs) and a $\mathrm{LWC}=0.5 \mathrm{~g} \mathrm{~m}^{-3}$ (characteristic of very dense clouds) at $298 \mathrm{~K}$ with $\mathrm{SZA}=20^{\circ}$. The length of each bar shows the best-guess estimation of the chemical sink corresponding to its color. In the case of aqueous photolysis, the cyan bars show an upper bound estimate of its contribution to the removal of each specific species at $298 \mathrm{~K}$. One of the major conclusions of this analysis is that even in conditions where aqueous processes are most favorable, $\mathrm{LWC}=0.5 \mathrm{~g} \mathrm{~m}^{-3}$, removal by aqueous photolysis remains a minor sink of the species investigated in Fig. 10. The only compounds with an appreciable aqueous photolysis contribution are hydrogen peroxide and methyl glyoxal. (However, aqueous photolysis may be important for more structurally complicated compounds that do not appear in Fig. 10. Published $\mathrm{OH}$ rate constants, gaseous absorption cross sections, and quantum yields are available only for relatively simple compounds.) At lower temperatures, the increased solubility of cloud and fog droplets slightly enhances this contribution, but even in an air mass with a $\mathrm{LWC}=0.5 \mathrm{~g} \mathrm{~m}^{-3}$ at $273 \mathrm{~K}$, liquid photolysis of hydrogen peroxide accounts for less than $20 \%$ of its removal. However, photolysis of aqueous $\mathrm{H}_{2} \mathrm{O}_{2}$ is a significant source of aqueous $\mathrm{OH}$; its rate of production is on the order of the rate of droplet scavenging from the gas phase (Zellner et al., 1990). A complete analysis detailing the magnitude of each of the chemical sinks at $273 \mathrm{~K}$ for species with published Henry's Law temperature dependences is presented in Appendix B.

Our analysis of the ratio of gas phase photolysis and aqueous phase photolysis can help guide the selection of compounds for future experiments. Aqueous photolysis absorption cross sections and quantum yields are not well established in the literature, but may be important parameters for specific compounds. Glyceraldehyde and pyruvic acid were not included in Fig. 10 due to the lack of published gaseous absorption cross sections and quantum yields. However, based on the results of Fig. 3, we expect aqueous photolysis to be a significant sink for these compounds. For compounds that were not analyzed in this manuscript, the potential significance of aqueous photolysis can be determined with knowledge of the Henry's law constant and the hydration equilibrium constants if hydration occurs in the aqueous phase.

For most acids in wet clouds, aqueous phase $\mathrm{OH}$ oxidation is more important that gas phase $\mathrm{OH}$ oxidation. For atmospherically relevant compounds without published aqueous rate constants, experiments designed to measure these values may prove to be fruitful. Since the ratio of the gas and aqueous phase $\mathrm{OH}$ removal rates is a strong function of LWC and the Henry's Law constant, one can determine additional species for which experimental measurements are warranted.

We have chosen to treat aqueous phase photolysis and oxidation separately, but in certain cases, photolytic cleavage may produce $\mathrm{OH}$ and other free radicals that will react with the organic precursor. This will effectively increase the quantum yield of photolysis for the removal of the precursor beyond what would be measured if the liberated $\mathrm{OH}$ was being quenched by a competing reaction. However, in the absence of photo-catalytic processes or chain reactions, we expect this potential enhancement to be small (at most a factor of 2 or 3 ) as in the case of methyl peroxide (Epstein et al., 2012).

As indicated in Fig. 9, the ratio of gas phase oxidation to gas phase photolysis is a complicated function of altitude and SZA. Gas phase absorption cross section and quantum yield measurements at $298 \mathrm{~K}$ and $1 \mathrm{~atm}$ may not provide enough information to describe the atmospheric behavior of certain organics especially at higher SZA. For example, photolysis of methyl glyoxal, and hydrogen peroxide relative to oxidation is enhanced at high latitudes $\left(\mathrm{SZA}>60^{\circ}\right)$ and altitudes compared to the ratio at $1 \mathrm{~atm}$. In the case of methyl glyoxal at solar zenith angles $<60^{\circ}$, photolysis relative to oxidation is suppressed at higher altitudes. In light of these complicated dependencies, we recommend caution when extrapolating room temperature and $1 \mathrm{~atm}$ measurements of photolysis quantum yields and absorption cross sections.

We have assumed that the organic molecules in our analysis do not interact with each other. While this assumption is 


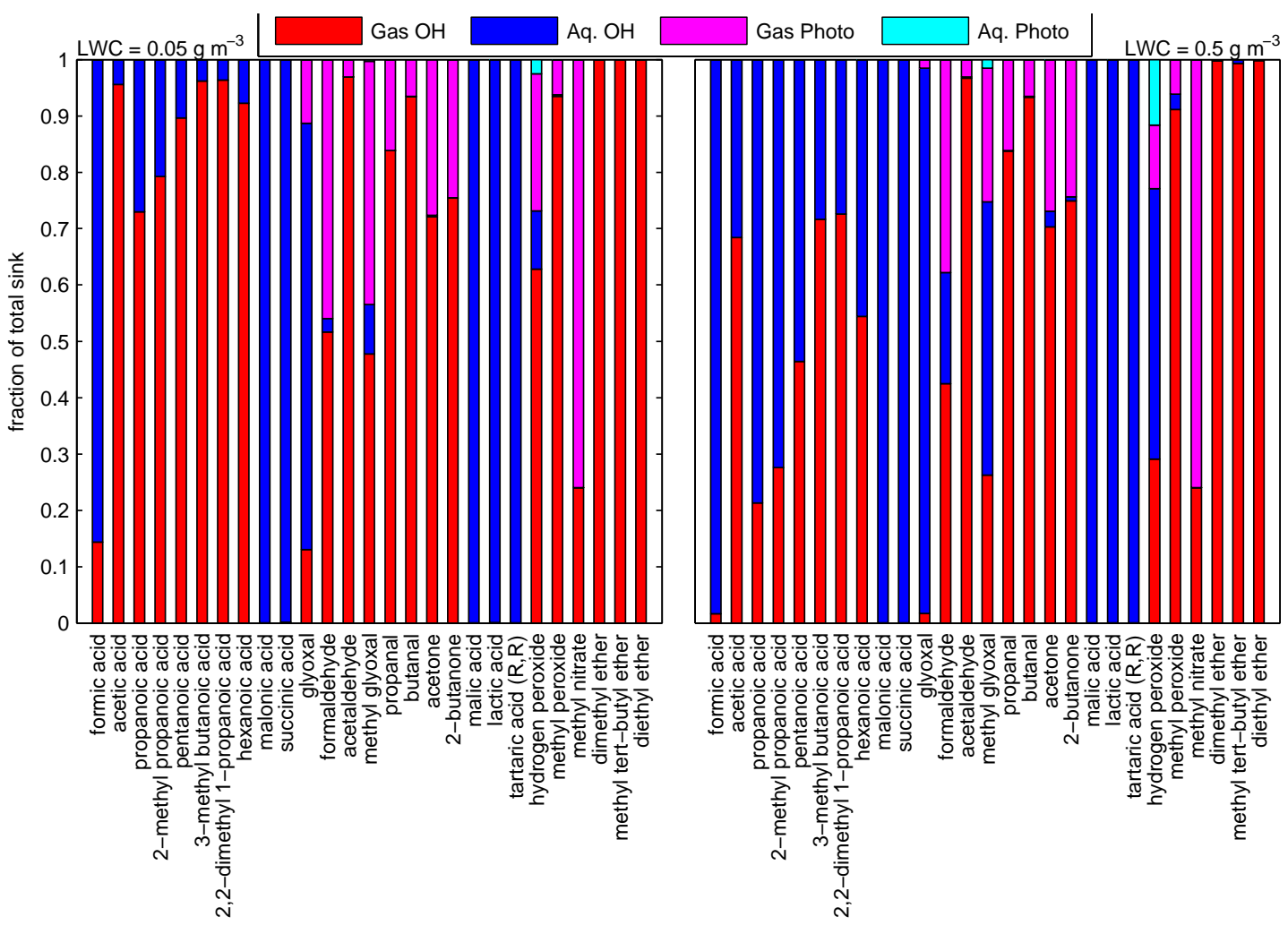

Fig. 10. Estimated magnitudes of each of the 4 chemical sinks investigated for compounds with sufficient published data. All acids are assumed to be in cloud or fog droplets at a $\mathrm{pH}=6$. Calculations were performed with a solar zenith angle of $20^{\circ}$. The right panel details selected species in a parcel with a $L W C=0.5 \mathrm{~g} \mathrm{~m}^{-3}$ at $298 \mathrm{~K}$ and represents the upper limit for the contribution of aqueous processes in all situations at $298 \mathrm{~K}$. The left panel shows the contribution of each of the four sinks in an air parcel with a more realistic $\mathrm{LWC}=0.05 \mathrm{~g} \mathrm{~m}{ }^{-3}$ at $298 \mathrm{~K}$. The contributions of aqueous processes in this panel are also an upper estimate for the selected LWC.

needed to constrain the complexity of interacting molecules and draw conclusions, it may not be appropriate in all conditions. For example, in a polluted environment, organics may compete for aqueous phase $\mathrm{OH}$ radicals in a cloud or fog droplet. A more complicated analysis is required to capture these effects.

\section{Appendix A}

\section{Equation derivations}

\section{A1 Derivation of $Z$}

We start with the rate laws for photolysis in the gas and aqueous phase:

$\frac{\mathrm{d} C_{x+h v}^{\mathrm{gas}}}{\mathrm{d} t}=-J_{x+h \nu}^{\mathrm{gas}} C_{x}^{\mathrm{gas}}$

$\frac{\mathrm{d} C_{x+h v}^{\mathrm{aq}}}{\mathrm{d} t}=-J_{x+h \nu}^{\mathrm{aq}} C_{x}^{\mathrm{aq}}$

where $C_{x}^{\text {gas }}$ is the gas phase concentration of species $x$ and $C_{x}^{\mathrm{aq}}$ is the aqueous phase concentration of $x$. We transform concentration units into a molar basis with the volume of the air parcel $\left(V_{\text {air }}\right)$ and the volume of water inside the air parcel $\left(V_{\mathrm{H}_{2} \mathrm{O}}\right)$.

$\frac{\mathrm{d} n_{x+h v}^{\text {gas }}}{\mathrm{d} t}=V_{\text {air }} \cdot \frac{\mathrm{d} C_{x+h v}^{\text {gas }}}{\mathrm{d} t}$

$\frac{\mathrm{d} n_{x+h v}^{\mathrm{aq}}}{\mathrm{d} t}=V_{\mathrm{H}_{2} \mathrm{O}} \cdot \frac{\mathrm{d} C_{x+h v}^{\mathrm{aq}}}{\mathrm{d} t}$

We define $Z$ as the ratio between these two molar rates:

$Z \equiv \frac{\frac{\mathrm{d} n_{x+h v}^{\mathrm{gas}}}{\mathrm{d} t}}{\frac{\mathrm{d} n_{x+h v}^{\mathrm{aq}}}{\mathrm{d} t}}$

The ratio of air and water volumes can be simplified with a volumetric cloud liquid water content $\left(\mathrm{LWC}_{\mathrm{v}}\right.$, volume of $\mathrm{H}_{2} \mathrm{O}$ /volume of air parcel):

$Z=\frac{V_{\mathrm{air}} \cdot \frac{\mathrm{d} C_{x+h \nu}^{\mathrm{gas}}}{\mathrm{d} t}}{V_{\mathrm{H}_{2} \mathrm{O}} \cdot \frac{\mathrm{d} C_{x+h \nu}^{\mathrm{aq}}}{\mathrm{d} t}}=\frac{1}{\mathrm{LWC}_{\mathrm{v}}} \cdot \frac{J_{x+h \nu}^{\mathrm{gas}} C_{x}^{\mathrm{gas}}}{J_{x+h \nu}^{\mathrm{aq}} C_{x}^{\mathrm{aq}}}$ 


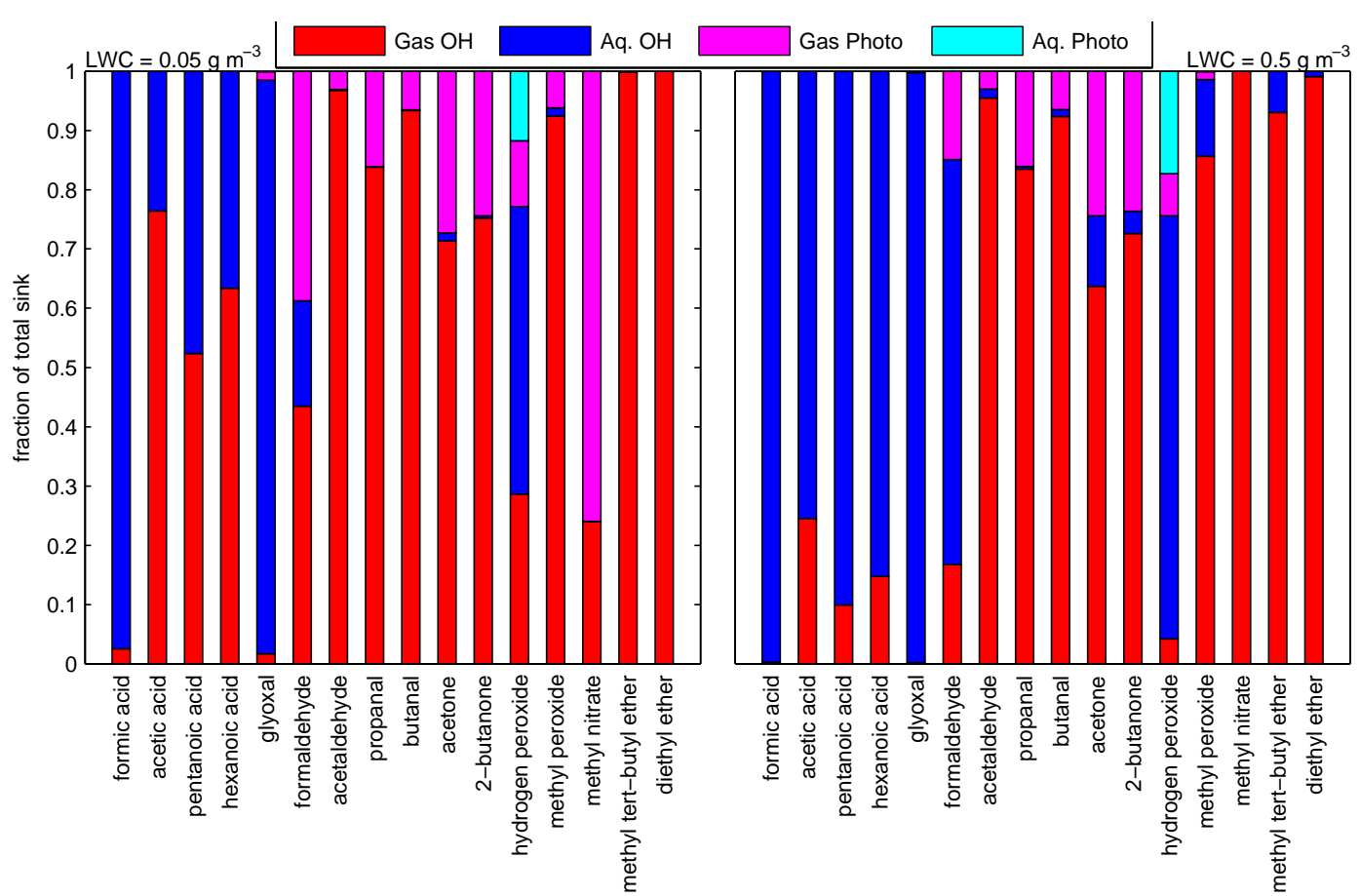

Fig. A1. Estimated magnitudes of each of the 4 chemical sinks investigated for compounds with sufficient published data. All acids are assumed to be in cloud or fog droplets at a $\mathrm{pH}=6$. Calculations were performed with a solar zenith angle of $20^{\circ}$. The right panel details selected species in a parcel with a $L W C=0.5 \mathrm{~g} \mathrm{~m}^{-3}$ at $273 \mathrm{~K}$ and represents the upper limit for the contribution of aqueous processes in all situations at $273 \mathrm{~K}$. The left panel shows the contribution of each of the 4 sinks in an air parcel with a more realistic $\mathrm{LWC}^{2}=0.05 \mathrm{~g} \mathrm{~m}^{-3}$ at $273 \mathrm{~K}$. The contributions of aqueous processes in this panel are also an upper estimate for the selected LWC.

where the volumetric liquid water volume is defined as:

$\mathrm{LWC}_{\mathrm{v}}=\frac{\mathrm{LWC}}{\rho_{\mathrm{H}_{2} \mathrm{O}}}$

The density of water is represented by $\rho_{\mathrm{H}_{2} \mathrm{O}}$ and LWC is the liquid water content in units of mass of water per volume of air parcel. We now introduce the Henry's law constant to describe the ratio of the aqueous phase concentration of $x$ $\left(C_{x}^{\mathrm{aq}}\right)$ and the partial pressure of $x\left(p_{x}^{\mathrm{gas}}\right)$.

$k_{H}=\frac{C_{x}^{\mathrm{aq}}}{p_{x}^{\mathrm{gas}}}$

Converting pressure to concentration units with the ideal gas constant and temperature yields the equilibrium ratio of gas and aqueous phase concentration of $x$ :

$\frac{C_{x}^{\mathrm{gas}}}{C_{x}^{\mathrm{aq}}}=\frac{1}{k_{H} R T}$

Our final working equation to decribe the ratio of the rate of gas phase photolysis to the rate of aqueous phase photolysis is:

$Z=\frac{1}{\mathrm{LWC}_{\mathrm{v}} \cdot k_{H} \cdot R \cdot T} \cdot\left(\frac{J_{x+h v}^{\mathrm{gas}}}{J_{x+h v}^{\mathrm{aq}}}\right)$

\section{A2 Derivation of $W$}

We start with the rate laws for oxidation of species $x$ in the gas and aqueous phase by $\mathrm{OH}$ :

$\frac{\mathrm{d} C_{x+\mathrm{OH}}^{\mathrm{gas}}}{\mathrm{d} t}=-k_{x+\mathrm{OH}}^{\mathrm{gas}} C_{x}^{\mathrm{gas}} C_{\mathrm{OH}}^{\mathrm{gas}}$

$\frac{\mathrm{d} C_{x+\mathrm{OH}}^{\mathrm{aq}}}{\mathrm{d} t}=-k_{x+\mathrm{OH}}^{\mathrm{aq}} C_{x}^{\mathrm{aq}} C_{\mathrm{OH}}^{\mathrm{aq}}$

Converting to molar units:

$\frac{\mathrm{d} n_{x+\mathrm{OH}}^{\mathrm{gas}}}{\mathrm{d} t}=V_{\mathrm{air}} \cdot \frac{\mathrm{d} C_{x+\mathrm{OH}}^{\mathrm{gas}}}{\mathrm{d} t}$

$\frac{\mathrm{d} n_{x+\mathrm{OH}}^{\mathrm{aq}}}{\mathrm{d} t}=V_{\mathrm{H}_{2} \mathrm{O}} \cdot \frac{\mathrm{d} C_{x+\mathrm{OH}}^{\mathrm{aq}}}{\mathrm{d} t}$

We define $W$ as the ratio between the loss rate due to gas phase oxidation and the loss rate due to aqueous oxidation:

$W \equiv \frac{\frac{\mathrm{d} n_{x+\mathrm{OH}}^{\mathrm{gas}}}{\mathrm{d} t}}{\frac{\mathrm{d} n_{x+\mathrm{OH}}^{\mathrm{aq}}}{\mathrm{d} t}}$ 
We eliminate the dependence of air and water volume with the volumetric liquid water content:

$$
W=\frac{V_{\mathrm{air}} \cdot \frac{\mathrm{d} C_{x+\mathrm{OH}}^{\mathrm{gas}}}{\mathrm{d} t}}{V_{\mathrm{H}_{2} \mathrm{O}} \cdot \frac{\mathrm{d} C_{x+\mathrm{OH}}^{\mathrm{aq}}}{\mathrm{d} t}}=\frac{1}{\mathrm{LWC}_{\mathrm{v}}} \cdot \frac{k_{x+\mathrm{OH}}^{\mathrm{gas}} C_{x}^{\mathrm{gas}} C_{\mathrm{OH}}^{\mathrm{gas}}}{k_{x+\mathrm{OH}}^{\mathrm{aq}} C_{x}^{\mathrm{aq}} C_{\mathrm{OH}}^{\mathrm{aq}}}
$$

Inserting the Henry's law constant to discribe the ratio of gas and aqueous phase concentrations yields the final working equation:

$$
W=\frac{1}{\mathrm{LWC}_{\mathrm{v}} \cdot k_{H} \cdot R \cdot T} \cdot \frac{k_{x+\mathrm{OH}}^{\mathrm{gas}}}{k_{x+\mathrm{OH}}^{\mathrm{aq}}} \cdot \frac{C_{\mathrm{OH}}^{\mathrm{gas}}}{C_{\mathrm{OH}}^{\mathrm{aq}}}
$$

\section{A3 Derivation of $Y$}

We start with rate laws describing gas phase oxidation by $\mathrm{OH}$ and gas phase photolysis

$$
\begin{aligned}
& \frac{\mathrm{d} C_{x+\mathrm{OH}}^{\mathrm{gas}}}{\mathrm{d} t}=-k_{x+\mathrm{OH}}^{\mathrm{gas}} C_{x}^{\mathrm{gas}} C_{\mathrm{OH}}^{\mathrm{gas}} \\
& \frac{\mathrm{d} C_{x+h \nu}^{\mathrm{gas}}}{\mathrm{d} t}=-J_{x+h \nu}^{\mathrm{gas}} C_{x}^{\mathrm{gas}}
\end{aligned}
$$

We define the ratio of these rates in molar units as $Y$ :

$$
Y \equiv \frac{\frac{\mathrm{d} n_{x+\mathrm{OH}}^{\mathrm{gas}}}{\mathrm{d} t}}{\frac{\mathrm{d} n_{x+h v}^{\mathrm{gas}}}{\mathrm{d} t}}
$$

Since both rates describe the gas phase, the ratio of molar rates is equal to the ratio of concentration-based rates:

$$
\frac{\frac{\mathrm{d} n_{x+\mathrm{OH}}^{\mathrm{gas}}}{\mathrm{d} t}}{\frac{\mathrm{d} n_{x+h v}^{\mathrm{gas}}}{\mathrm{d} t}}=\frac{\frac{\mathrm{d} C_{x+\mathrm{OH}}^{\mathrm{gas}}}{\mathrm{d} t}}{\frac{\mathrm{d} C_{x+h v}^{\mathrm{gas}}}{\mathrm{d} t}}
$$

Inserting Eqs. (A18) and (A19) into Eq. (A21) yields our final working equation for $Y$ :

$$
Y=\frac{k_{x+\mathrm{OH}}^{\mathrm{gas}} C_{\mathrm{OH}}^{\mathrm{gas}}}{J_{x+h v}^{\mathrm{gas}}}
$$

\section{Appendix B}

\section{Chemical sink analysis at different temperatures}

$Z$ as a function of temperature can be calculated from $Z$ at 298 K. Both Henry's Law constants and for carbonyls, hydration equilibrium constants are sensitive to temperature. When temperature dependent Henry's Law data are available, they are typically fit to the function (Sander et al., 2011):

$\ln k_{H x}=A+B \cdot T^{-1}+C \cdot \ln (T)$ where $A, B$, and $C$ are fitting parameters. $Z$ calculated at $T_{1}$ can be adjusted to temperature $T_{2}$ with the unitless correction factor, $\mathrm{CF}_{\text {Hlaw }}$ :

$\mathrm{CF}_{\text {Hlaw }}{ }^{T_{1} \rightarrow T_{2}}=e^{B \cdot\left(\frac{1}{T_{1}}-\frac{1}{T_{2}}\right)+C \cdot \ln \left(\frac{T_{1}}{T_{2}}\right)}$

Hydration equilibrium constants are also a function of temperature. For a di-carbonyl, $Z$ calculated at $T_{1}$ can be adjusted to temperature $T_{2}$ with the unitless correction factor, $\mathrm{CF}_{\text {Khyd }}$, which accounts for this temperature dependence:

$\mathrm{CF}_{\text {Khyd }}^{T_{1} \rightarrow T_{2}}=\frac{e^{\frac{\Delta S_{\text {hyd }}}{R}-\frac{\Delta H_{\text {hyd }}}{R \cdot T_{2}}}+1}{e^{\frac{\Delta S_{\text {hyd }}}{R}-\frac{\Delta H_{\text {hyd }}}{R \cdot T_{1}}}+1}$

where $\Delta S_{\text {hyd }}$ is the change in entropy upon hydration and $\Delta H_{\text {hyd }}$ is the change in enthalpy upon hydration. $Z$ at $T_{2}$ is the product of the correction factors and $Z$ at $T_{1}$ :

$Z\left(T_{2}\right)=\mathrm{CF}_{\text {Hlaw }}^{T_{1} \rightarrow T_{2}} \cdot \mathrm{CF}_{\text {Khyd }}^{T_{1} \rightarrow T_{2}} \cdot Z\left(T_{1}\right)$

The factor $W$ can also be corrected for other temperatures by accounting for differences in both the Henry's Law parameter and the ratio of the gaseous and aqueous rate constants. $W$ calculated at $T_{1}$ can be adjusted to its value at $\mathrm{T}_{2}$ :

$W\left(T_{2}\right)=\mathrm{CF}_{\text {Hlaw }}^{T_{1} \rightarrow T_{2}} \cdot \mathrm{CF}_{k}^{T_{1} \rightarrow T_{2}} \cdot W\left(T_{1}\right)$

where $\mathrm{CF}_{k}$ accounts for the temperature dependence on the rate constants:

$\mathrm{CF}_{k}^{T_{1} \rightarrow T_{2}}=\exp \left[\left(\frac{1}{T_{2}}-\frac{1}{T_{1}}\right)\left(\frac{E_{\mathrm{A}}^{\mathrm{aq} .}}{R}-\frac{E_{A}^{\mathrm{gas}}}{R}\right)\right]$

and $E_{\mathrm{A}}^{\text {aq. }}$ is the activation energy of the $\mathrm{OH}$ oxidation reaction in the aqueous phase and $E_{\mathrm{A}}^{\mathrm{gas}}$ is the activation energy of the gas phase reaction.

Using Eqs. (B4) and (B5), we can predict $Z$ and $W$ factors at $273 \mathrm{~K}$ from the values calculated at $298 \mathrm{~K}$. The correction factor used to account for the changing gas solubility parameters at different temperatures, $\mathrm{CF}_{\text {Hlaw }}$, is dependent on the fitting parameters used to correlate Henry's Law parameters with temperatures (see Eq. B2). For most compounds, these fitting parameters are available in the literature (Sander et al., 2011; Sander, 1999). Typically $C$ is small, and can be safely set to 0 . For the compounds investigated, $B$ ranges from 4700 to $7700 \mathrm{~K}$, yielding correction factors of 0.04 to 0.004 going from temperatures of 298 to $273 \mathrm{~K}$. This correction factor is significant and could change the magnitude of $Z$ by a few orders of magnitude while changes in the percent hydrated have a relatively small effect. Therefore, with the lack of temperature dependant hydration equilibrium data for many relevant compounds and the relatively small effect on $Z$, we only address changes due to increased Henry's Law parameters at depressed temperatures. 
$W$ can also be corrected by $\mathrm{CF}_{k}$, which captures the temperature dependence in the gas and aqueous $\mathrm{OH}$ rate constants. However, the availability of temperature dependent rate data for the compounds investigated is limited. Fortunately, $\mathrm{CF}_{k}$ tends to be on the order of 1 for reasonably small temperature changes. For example, when the activation energy of the aqueous and gaseous reactions differ by $2500 \mathrm{~K}$, (an upper estimate from a selection of published $\mathrm{OH}$ rate constants for several water soluble compounds) $\mathrm{CF}_{k}^{298 \rightarrow 273}=$ 0.5. Overestimating or underestimating our value of $W$ by not correcting by this factor will not significantly change the results of our analysis. The lack of published activation energies and the limited influence temperature changes have on $\mathrm{CF}_{k}$ motivate the assumption that $\mathrm{CF}_{k}$ is unity. $Y$ may also depend on temperature. Absorption cross section and quantum yield data are extremely limited, but for the four species for which we determined $Y$ as a function of SZA and altitude, $Y$ was not a strong function of temperature. Therefore, we assume that between $298 \mathrm{~K}$ and $273 \mathrm{~K}$ the magnitude of $Y$ will not change as to affect the results of our analysis.

Figure A1 shows the magnitude of each chemical sink for the compounds with published Henry's Law temperature dependences at $273 \mathrm{~K}$. In general, aqueous processes play a more significant role due to their enhanced solubility, but for the species investigated, aqueous photolysis still remains a minor sink.

\section{Appendix C}

\section{Nomenclature and units}

Variable, typical units, and definition are presented in their order of appearance in the text.

$$
\begin{aligned}
& J\left[\mathrm{~s}^{-1}\right] \\
& F_{\mathrm{A}}\left[\mathrm{cm}^{-2} \mathrm{~s}^{-1} \mathrm{~nm}^{-1}\right] \quad \text { actinic flux } \\
& \sigma\left[\mathrm{cm}^{2}\right] \quad \text { absorption cross section } \\
& \Phi \text { [unitless] quantum yield of } \\
& \lambda[\mathrm{nm}] \\
& \operatorname{LWC}\left[\frac{\mathrm{g}_{\mathrm{H}_{2} \mathrm{O}}}{\mathrm{m}_{\text {air }}^{3}}\right] \\
& Z \text { [unitless] } \\
& n_{x}[\mathrm{~mol}] \\
& R\left[\frac{\mathrm{Latm}}{\mathrm{molK}}\right] \text { or } R\left[\frac{J}{\mathrm{molK}}\right] \\
& T[K] \\
& \begin{array}{l}
\text { quantum yield } \\
\text { photolysis }
\end{array} \\
& \text { wavelength of light } \\
& \text { Liquid water content in } \\
& \text { terms of the mass of water } \\
& \text { per volume of air } \\
& \text { ratio of the rate of gas phase } \\
& \text { photolysis to the rate of } \\
& \text { aqueous phase photolysis } \\
& \text { moles of species } x \\
& \text { ideal gas constant } \\
& \text { temperature }
\end{aligned}
$$

volume based liquid water content (water volume per volume of air)

$$
\begin{aligned}
& k_{H x}\left[\frac{\mathrm{mol}_{x}}{\mathrm{~L}_{\mathrm{H}_{2} \mathrm{O}} \mathrm{atm}}\right] \\
& J_{x+h \nu}^{\mathrm{gas}}\left[\mathrm{s}^{-1}\right] \\
& J_{x+h \nu}^{\mathrm{aq}}\left[\mathrm{s}^{-1}\right]
\end{aligned}
$$

$t[\mathrm{~s}]$

$$
K_{\text {hyd }}[\text { unitless] }
$$$$
\alpha_{N} \text { [unitless] }
$$$$
\alpha_{\text {free [unitless] }}
$$

$\alpha_{\text {hyd }}$ [unitless]

$$
\beta_{N} \text { [unitless] }
$$

$\beta_{\text {free [unitless] }}$

$\beta_{\text {hyd }}$ [unitless]

$\beta_{\text {part_hyd [unitless] }}$

$\gamma_{x}$ [unitless]

$W$ [unitless]

$$
\begin{aligned}
& k_{x+\mathrm{OH}}^{\mathrm{gas}}\left[\mathrm{m}_{\mathrm{air}}^{3} \mathrm{~mol}^{-1} \mathrm{~s}^{-1}\right] \\
& k_{x+\mathrm{OH}}^{\mathrm{aq}}\left[\mathrm{m}_{\mathrm{H}_{2} \mathrm{O}}^{3} \mathrm{~mol}^{-1} \mathrm{~s}^{-1}\right]
\end{aligned}
$$

Henry's Law constant of species $x$

photolysis rate constant of species $x$ in the gas phase

photolysis rate constant of species $x$ in the aqueous phase

time

hydration equillibrium

constant

mole fraction of form $N$ in the aqueous phase upon hydration

mole fraction of the free form (unhydrated) in solution at equilibrium

mole fraction of the hydrated form in solution at equilibrium

normalization constant for the photolysis rate constant of form $N$

normalization constant for the photolysis rate constant of the free form

normalization constant for the photolysis rate constant of the hydrated form

normalization constant for the photolysis rate constant of the partially hydrated form

constant used to penalize the aqueous photolysis rate of species $x$ for the presence of non-photolabile gem-diol groups

ratio of the rate of gas phase reaction with $\mathrm{OH}$ to the rate of aqueous phase reaction with $\mathrm{OH}$

gas phase rate constant for the reaction of $x$ with $\mathrm{OH}$

aqueous phase rate constant for the reaction of $x$ with $\mathrm{OH}$ 


$$
\begin{aligned}
& C_{\mathrm{OH}}^{\mathrm{gas}}\left[\frac{\mathrm{mol} \mathrm{OH}_{\mathrm{gas}}}{\mathrm{m}_{\mathrm{gas}}^{3}}\right] \\
& C_{\mathrm{OH}}^{\mathrm{aq}}\left[\frac{\mathrm{mol}_{\mathrm{OH}}}{\mathrm{m}_{\mathrm{H}_{2} \mathrm{O}}^{3}}\right] \\
& C_{x}^{\mathrm{gas}}\left[\frac{\mathrm{mol}_{x}}{\mathrm{~m}_{\mathrm{gas}}^{3}}\right] \\
& C_{x}^{\mathrm{aq}}\left[\frac{\mathrm{mol}_{x}}{\mathrm{~m}_{\mathrm{H}_{2} \mathrm{O}}^{3}}\right]
\end{aligned}
$$$$
f_{\mathrm{A}^{-}} \text {[unitless] }
$$

$f_{\text {HA }}$ [unitless]

$Y$ [unitless]

SZA [deg latitude]

$z[\mathrm{~km}]$

$\Gamma\left[\mathrm{Kkm}^{-1}\right]$

$\Re$ [unitless]

DN [unitless]

$\mathrm{CF}_{\text {Hlaw }}^{T_{1} \rightarrow T_{2}}$ [unitless]

$\mathrm{CF}_{\text {Khyd }}^{T_{1} \rightarrow T_{2}}$ [unitless]

$\Delta S_{\mathrm{hyd}}\left[\mathrm{J} \mathrm{mol}^{-1} \mathrm{~K}^{-1}\right]$

$\Delta H_{\text {hyd }}\left[\mathrm{J} \mathrm{mol}^{-1}\right]$ concentration of $\mathrm{OH}$ in the gas phase

concentration of $\mathrm{OH}$ in the aqueous phase

concentration of species $x$ in the gas phase

concentration of species $x$ in the aqueous

mole fraction of the acid that is in the ionized form at equilibrium

mole fraction of the acid that is in the non-ionized form at equilibrium

ratio of the rate of gas phase reaction with $\mathrm{OH}$ to the rate of gas phase photolysis

solar zenith angle

altitude

average lapse rate

ratio of the observed aqueous phase concentration to the predicted aqueous phase concentration using Henry's law and the observed gas phase concentration

parameter (defined in this work) that indicates the ratio of the rate of gas phase reaction with $\mathrm{OH}$ relative to the rate of aqueous phase reaction with $\mathrm{OH}$

correction factor used to adjust $Z$ and $W$ due to the temperature dependance of Henry's Law constants

correction factor used to adjust $Z$ and $W$ due to the temperature dependance of hydration equillibrium

change in entropy upon hydration

change in enthalpy upon hydration

$$
\mathrm{CF}_{k}^{T_{1} \rightarrow T_{2}} \text { [unitless] }
$$

correction factor used to adjust $W$ due to the temperature dependance of $\mathrm{OH}$ rate constants

$$
\begin{aligned}
& E_{\mathrm{A}}^{\mathrm{aq}}\left[\mathrm{J} \mathrm{mol}^{-1}\right] \\
& E_{\mathrm{A}}^{\mathrm{gas}}\left[\mathrm{J} \mathrm{mol}^{-1}\right]
\end{aligned}
$$

activation energy of species $x$ in the aqueous phase

activation energy of species $x$ in the gas phase

$\rho_{\mathrm{H}_{2} \mathrm{O}}\left[\frac{\mathrm{kg}_{\mathrm{H}_{2} \mathrm{O}}}{\mathrm{m}_{\mathrm{H}_{2} \mathrm{O}}^{3}}\right]$

$V_{\text {air }}\left[\mathrm{m}_{\text {air }}^{3}\right]$ the density of water

$V_{\mathrm{H}_{2} \mathrm{O}}\left[\mathrm{m}_{\mathrm{H}_{2} \mathrm{O}}^{3}\right]$ air volume

water volume

\section{Supplementary material related to this article is available online at: http://www.atmos-chem-phys.net/12/ 8205/2012/acp-12-8205-2012-supplement.pdf.}

Acknowledgements. The authors would like to acknowledge the National Science Foundation grants ATM-0831518 and CHE0909227 for funding this work.

Edited by: V. F. McNeill

\section{References}

Albinet, A., Minero, C., and Vione, D.: Phototransformation processes of 2,4-dinitrophenol, relevant to atmospheric water droplets, Chemosphere, 80, 753-758, 2010.

Andreae, M. O. and Crutzen, P. J.: Atmospheric Aerosols: Biogeochemical Sources and Role in Atmospheric Chemistry, Science, 276, 1052-1058, doi:10.1126/science.276.5315.1052, 1997.

Atkinson, R.: A structure-activity relationship for the estimation of rate constants for the gas-phase reactions of $\mathrm{OH}$ radicals with organic compounds, Int. J. Chem. Kinet., 19, 799-828, doi:10.1002/kin.550190903, 1987.

Atkinson, R.: Estimation of gas-phase hydroxyl radical rate constants for organic chemicals, Environ. Toxicol. Chem., 7, 435442, doi:10.1002/etc.5620070604, 1988.

Atkinson, R.: Gas-phase tropospheric chemistry of organic compounds: A review, Atmos. Environ. A-Gen., 24, 1-41, 1990.

Atkinson, R.: Kinetics and Mechanisms of the Gas-Phase Reactions of the $\mathrm{NO}_{3}$ Radical with Organic Compounds, J. Phys. Chem. Ref. Data, 20, 459-507, 1991.

Atkinson, R. and Arey, J.: Atmospheric Degradation of Volatile Organic Compounds, Chem. Rev., 103, 4605-4638, doi:10.1021/cr0206420, 2003.

Atkinson, R., Baulch, D. L., Cox, R. A., Crowley, J. N., Hampson, R. F., Hynes, R. G., Jenkin, M. E., Rossi, M. J., Troe, J., and IUPAC Subcommittee: Evaluated kinetic and photochemical data for atmospheric chemistry: Volume II - gas phase reactions of organic species, Atmos. Chem. Phys., 6, 3625-4055, doi:10.5194/acp-6-3625-2006, 2006. 
Audiffren, N., Renard, M., Buisson, E., and Chaumerliac, N.: Deviations from the Henry's law equilibrium during cloud events: a numerical approach of the mass transfer between phases and its specific numerical effects, Atmos. Res., 49, 139-161, 1998.

Bailey, P. S.: Organic chemistry, vol. 39, pt. 1: Ozonation in organic chemistry, vol. 1: Olefinic compounds; Academic Press, 1978.

Bateman, A. P., Nizkorodov, S. A., Laskin, J., and Laskin, A.: Photolytic processing of secondary organic aerosols dissolved in cloud droplets, PCCP, 13, 12199-12212, 2011.

Bell, R. P. and Gold, V.: The Reversible Hydration of Carbonyl Compounds, in: Adv. Phys. Org. Chem., Academic Press, 1-29, 1966.

Bell, R. P. and McDougall, A. O.: Hydration equilibria of some aldehydes and ketones, Trans. Faraday Soc., 56, 1281-1285, 1960.

Buxton, G. V., Greenstock, C. L., Helman, W. P., and Ross, A. B.: Critical Review of rate constants for reactions of hydrated electrons, hydrogen atoms and hydroxyl radicals in aqueous Solution, J. Phys. Chem. Ref. Data, 17, 513-886, 1988.

Calvert, J. G. and Pitts, J. N.: Photochemistry, Wiley, 1966.

Chaumerliac, N., Leriche, M., and Audiffren, N.: Modeling of scavenging processes in clouds: some remaining questions about the partitioning of gases among gas and liquid phases, Atmos. Res., 53, 29-43, 2000.

Chebbi, A. and Carlier, P.: Carboxylic acids in the troposphere, occurrence, sources, and sinks: A review, Atmos. Environ., 30, 4233-4249, 1996.

Chu, L. and Anastasio, C.: Formation of Hydroxyl Radical from the Photolysis of Frozen Hydrogen Peroxide, J. Phys. Chem. A, 109, 6264-6271, doi:10.1021/jp051415f, 2005.

Czaplicka, M.: Photo-degradation of chlorophenols in the aqueous solution, J. Hazard. Mater., 134, 45-59, 2006.

De Bruyn, W. J., Swartz, E., Hu, J. H., Shorter, J. A., Davidovits, P., Worsnop, D. R., Zahniser, M. S., and Kolb, C. E.: Henry's law solubilities and Setchenow coefficients for biogenic reduced sulfur species obtained from gas-liquid uptake measurements, J. Geophys. Res., 100, 7245-7251, doi:10.1029/95jd00217, 1995.

Donahue, N. M., Robinson, A. L., and Pandis, S. N.: Atmospheric organic particulate matter: from smoke to secondary organic aerosol, Atmos. Environ., 43, 94-106, 2009.

Dong, S. and Dasgupta, P. K.: Solubility of gaseous formaldehyde in liquid water and generation of trace standard gaseous formaldehyde, Environ. Sci. Technol., 20, 637-640, doi:10.1021/es00148a016, 1986.

Epstein, S. A., Shemesh, D., Tran, V. T., Nizkorodov, S. A., and Gerber, R. B.: Absorption spectra and photolysis of methyl peroxide in liquid and frozen water, J. Phys. Chem. A, 24, 6068-6077, 2012.

Ervens, B. and Volkamer, R.: Glyoxal processing by aerosol multiphase chemistry: towards a kinetic modeling framework of secondary organic aerosol formation in aqueous particles, Atmos. Chem. Phys., 10, 8219-8244, doi:10.5194/acp-10-8219-2010, 2010.

Ervens, B., George, C., Williams, J. E., Buxton, G. V., Salmon, G. A., Bydder, M., Wilkinson, F., Dentener, F., Mirabel, P., Wolke, R., and Herrmann, H.: CAPRAM 2.4 (MODAC mechanism): An extended and condensed tropospheric aqueous phase mechanism and its application, J. Geophys. Res., 108, 4426, doi:10.1029/2002jd002202, 2003a.
Ervens, B., Gligorovski, S., and Herrmann, H.: Temperaturedependent rate constants for hydroxyl radical reactions with organic compounds in aqueous solutions, PCCP, 5, 1811-1824, 2003b.

Ervens, B., Turpin, B. J., and Weber, R. J.: Secondary organic aerosol formation in cloud droplets and aqueous particles (aqSOA): a review of laboratory, field and model studies, Atmos. Chem. Phys., 11, 11069-11102, doi:10.5194/acp-1111069-2011, 2011.

Farkas, L. and Hirshberg, Y.: The Photochemical Decomposition of Aliphatic Alcohols in Aqueous Solution, J. Am. Chem. Soc., 59, 2450-2453, doi:10.1021/ja01290a104, 1937.

Faust, B. C.: Photochemistry of clouds, fogs, and aerosols, Environ. Sci. Technol., 28, 216A-222A, doi:10.1021/es00054a712, 1994.

Faust, B. C. and Allen, J. M.: Aqueous-phase photochemical formation of hydroxyl radical in authentic cloudwaters and fogwaters, Environ. Sci. Technol., 27, 1221-1224, doi:10.1021/es00043a024, 1993.

Faust, B. C., Powell, K., Rao, C. J., and Anastasio, C.: Aqueousphase photolysis of biacetyl (An alpha-dicarbonyl compound): A sink for biacetyl, and a source of acetic acid, peroxyacetic acid, hydrogen peroxide, and the highly oxidizing acetylperoxyl radical in aqueous aerosols, fogs, and clouds, Atmos. Environ., 31, 497-510, 1997.

Finlayson-Pitts, B. J. and Pitts, J. N.: Chemistry of the Upper and Lower Atmosphere, Academic Press, San Diego, 2000.

Gelencsér and Varga: Evaluation of the atmospheric significance of multiphase reactions in atmospheric secondary organic aerosol formation, Atmos. Chem. Phys., 5, 2823-2831, doi:10.5194/acp5-2823-2005, 2005.

Goldstein, A. H. and Galbally, I. E.: Known and Unexplored Organic Constituents in the Earth's Atmosphere, Environ. Sci. Technol., 41, 1514-1521, doi:10.1021/es072476p, 2007.

Goldstein, S., Aschengrau, D., Diamant, Y., and Rabani, J.: Photolysis of aqueous $\mathrm{H} 2 \mathrm{O} 2$ : quantum yield and applications for polychromatic UV actinometry in photoreactors, Environ. Sci. Technol., 41, 7486-7490, doi:10.1021/es071379t, 2007.

Graedel, T. E. and Goldberg, K. I.: Kinetic Studies of Raindrop Chemistry 1. Inorganic and Organic Processes, J. Geophys. Res., 88, 10865-10882, doi:10.1029/JC088iC15p10865, 1983.

Graedel, T. E. and Weschler, C. J.: Chemistry within aqueous atmospheric aerosols and raindrops, Rev. Geophys., 19, 505-539, doi:10.1029/RG019i004p00505, 1981.

Guzmán, M. I., Colussi, A. J., and Hoffmann, M. R.: Photoinduced oligomerization of aqueous pyruvic acid, J. Phys. Chem. A, 110, 3619-3626, doi:10.1021/jp056097z, 2006.

Guzmán, M. I., Hoffmann, M. R., and Colussi, A. J.: Photolysis of pyruvic acid in ice: Possible relevance to $\mathrm{CO}$ and $\mathrm{CO}_{2}$ ice core record anomalies, J. Geophys. Res., 112, D10123, doi:10.1029/2006jd007886, 2007.

Haag, W. R. and Yao, C. C. D.: Rate constants for reaction of hydroxyl radicals with several drinking water contaminants, Environ. Sci. Technol., 26, 1005-1013, doi:10.1021/es00029a021, 1992.

Hirshberg, Y. and Farkas, L.: On the Photochemical Decomposition of Aliphatic Aldehydes in Aqueous Solutions, J. Am. Chem. Soc., 59, 2453-2457, doi:10.1021/ja01290a105, 1937. 
Hobbs, P. V.: Aerosol-Cloud-Climate Interactions, Academic Press, 1993.

Hummel, J. R. and Reck, R. A.: A Global Surface Albedo Model, J. Appl. Meteorol., 18, 239-253, 1979.

Kolb, C. E., Jayne, J. T., Worsnop, D. R., and Davidovits, P.: Solubility data requirements and new experimental methods in atmospheric aerosol research, Pure and applied chemistry, Research Triangle Park, NC, ETATS-UNIS, 10 pp., 1997.

Kwok, E. S. C. and Atkinson, R.: Estimation of hydroxyl radical reaction rate constants for gas-phase organic compounds using a structure-reactivity relationship: An update, Atmos. Environ., 29, 1685-1695, 1995.

Larsen, M. C. and Vaida, V.: Near Infrared Photochemistry of Pyruvic Acid in Aqueous Solution, J. Phys. Chem. A, 116, 5840-5846, doi:10.1021/jp2087972, 2012.

Le Botlan, D. J., Mechin, B. G., and Martin, G. J.: Proton and carbon-13 nuclear magnetic resonance spectrometry of formaldehyde in water, Anal. Chem., 55, 587-591, doi:10.1021/ac00254a041, 1983.

Ledger, M. B. and Porter, G.: Primary photochemical processes in aromatic molecules. Part 15. - The photochemistry of aromatic carbonyl compounds in aqueous solution, J. Chem. Soc. Faraday T., 68, 539-553, 1972.

Lee, M., Heikes, B. G., and O'Sullivan, D. W.: Hydrogen peroxide and organic hydroperoxide in the troposphere: a review, Atmos. Environ., 34, 3475-3494, 2000.

Leermakers, P. A. and Vesley, G. F.: The Photochemistry of alphaKeto Acids and alpha-Keto Esters. I. Photolysis of Pyruvic Acid and Benzoylformic Acid, J. Am. Chem. Soc., 85, 3776-3779, doi:10.1021/ja00906a013, 1963.

Leriche, M., Voisin, D., Chaumerliac, N., Monod, A., and Aumont, B.: A model for tropospheric multiphase chemistry: application to one cloudy event during the CIME experiment, Atmos. Environ., 34, 5015-5036, 2000.

Limbeck, A. and Puxbaum, H.: Dependence of in-cloud scavenging of polar organic aerosol compounds on the water solubility, J. Geophys. Res., 105, 19857-19867, doi:10.1029/2000jd900123, 2000.

Madronich, S.: Photodissociation in the Atmosphere 1. Actinic Flux and the Effects of Ground Reflections and Clouds, J. Geophys. Res., 92, 9740-9752, doi:10.1029/JD092iD08p09740, 1987.

Marini, A., Munoz-Losa, A., Biancardi, A., and Mennucci, B.: What is Solvatochromism?, J. Phys. Chem. B, 114, 1712817135, doi:10.1021/jp1097487, 2010.

Mayer, B. and Madronich, S.: Actinic flux and photolysis in water droplets: Mie calculations and geometrical optics limit, Atmos. Chem. Phys., 4, 2241-2250, doi:10.5194/acp-4-2241-2004, 2004.

Monod, A., Poulain, L., Grubert, S., Voisin, D., and Wortham, H.: Kinetics of $\mathrm{OH}$-initiated oxidation of oxygenated organic compounds in the aqueous phase: new rate constants, structure activity relationships and atmospheric implications, Atmos. Environ., 39, 7667-7688, 2005.

Monod, A., Chevallier, E., Durand Jolibois, R., Doussin, J. F., Picquet-Varrault, B., and Carlier, P.: Photooxidation of methylhydroperoxide and ethylhydroperoxide in the aqueous phase under simulated cloud droplet conditions, Atmos. Environ., 41, 24122426, 2007.
Moortgat, G. K.: Important photochemical processes in the atmosphere, Pure Appl. Chem., 73, 487-490, 2001.

Nguyen, T. B., Laskin, A., Laskin, J., and Nizkorodov, S. A.: Direct aqueous photochemistry of isoprene high-nox secondary organic aerosol, PCCP, 14, 9702-9714, 2012.

Pankow, J. F. and Asher, W. E.: SIMPOL.1: a simple group contribution method for predicting vapor pressures and enthalpies of vaporization of multifunctional organic compounds, Atmos. Chem. Phys., 8, 2773-2796, doi:10.5194/acp-8-27732008, 2008.

Rohrer, F. and Berresheim, H.: Strong correlation between levels of tropospheric hydroxyl radicals and solar ultraviolet radiation, Nature, 442, 184-187, 2006.

Ruggaber, A., Dlugi, R., Bott, A., Forkel, R., Herrmann, H., and Jacobi, H. W.: Modelling of radiation quantities and photolysis frequencies in the aqueous phase in the troposphere, Atmos. Environ., 31, 3137-3150, 1997.

Sander, R.: Compilation of Henry's Law constants for inorganic and organic species of potential importance in environmental chemistry (Version 3), available at: http://www.henrys-law.org, 1999.

Sander, S. P., Abbatt, J., Barker, J. R., Burkholder, J. B., Friedl, R. R., Golden, D. M., Huie, R. E., Kolb, C. E., Kurylo, M. J., Moortgat, G. K., Orkin, V. L., and Wine, P. H.: Chemical kinetics and photochemical data for use in atmospheric studies: Evaluation number 17, JPL Publication 10-6, Jet Propulsion Laboratory, Pasadena, available at: http://jpldataeval.jpl.nasa.gov, 2011.

Saxena, P. and Hildemann, L. M.: Water-soluble organics in atmospheric particles: A critical review of the literature and application of thermodynamics to identify candidate compounds, J. Atmos. Chem., 24, 57-109, 1996.

Schwarzenbach, R. P., Gschwend, P. M., and Imboden, D. M.: Frontmatter, in: Environmental Organic Chemistry, John Wiley \& Sons, Inc., i-xiii, 2005.

Seinfeld, J. and Pandis, S.: Atmospheric Chemistry and Physics, John Wiley and Sons, Inc., New York, 1998.

Vaitilingom, M., Amato, P., Sancelme, M., Laj, P., Leriche, M., and Delort, A. M.: Contribution of microbial activity to carbon chemistry in clouds, Appl. Environ. Microbiol., 76, 23-29, 2010.

Vione, D., Maurino, V., Minero, C., Pelizzetti, E., Harrison, M. A. J., Olariu, R.-I., and Arsene, C.: Photochemical reactions in the tropospheric aqueous phase and on particulate matter, Chem. Soc. Rev., 35, 441-453, 2006.

Wallace, J. M. and Hobbs, P. V.: Atmospheric Science: An Introductory Survey, in: International Geophysics Series, edited by: Dmowska, R., Hartmann, D., and Rossby, H. T., Academic Press, 2006.

Wan, H. B., Wong, M. K., and Mok, C. Y.: Comparative study on the quantum yields of direct photolysis of organophosphorus pesticides in aqueous solution, J. Agric. Food. Chem., 42, 2625-2630, doi:10.1021/jf00047a046, 1994.

Winiwarter, W., Fierlinger, H., Puxbaum, H., Facchini, M. C., Arends, B. G., Fuzzi, S., Schell, D., Kaminski, U., Pahl, S., Schneider, T., Berner, A., Solly, I., and Kruisz, C.: Henry's law and the behavior of weak acids and bases in fog and cloud, J. Atmos. Chem., 19, 173-188, doi:10.1007/bf00696588, 1994.

Xu, H., Wentworth, P. J., Howell, N. W., and Joens, J. A.: Temperature dependent near-UV molar absorptivities of aliphatic aldehydes and ketones in aqueous solution, Spectrochim. Acta A, 49, 1171-1178, 1993. 
Zellner, R., Exner, M., and Herrmann, H.: Absolute OH quantum yields in the laser photolysis of nitrate, nitrite and dissolved $\mathrm{H}_{2} \mathrm{O}_{2}$ at 308 and $351 \mathrm{~nm}$ in the temperature range $278-353 \mathrm{~K}$, J. Atmos. Chem., 10, 411-425, doi:10.1007/bf00115783, 1990.
Zimmerman, H. E. and Sandel, V. R.: Mechanistic organic photochemistry. II.1,2 Solvolytic photochemical reactions, J. Am. Chem. Soc., 85, 915-922, doi:10.1021/ja00890a019, 1963. 